\title{
MELHORAMENTO DO TRIGO: XXII. COMPORTAMENTO DE LINHAGENS ORIGINÁRIAS DE TRIGOS DE INVERNO E DE PRIMAVERA NO ESTADO DE SÃO PAULO $\left({ }^{1}\right)$
}

\author{
CARLOS EDUARDO DE OLIVEIRA CAMARGO $\left({ }^{2,5}\right)$, JOÃO CARLOS FELÍCIO $\left.i^{2,5}\right)$, \\ ANTONIO WILSON PENTEADO FERREIRA FILHO $(2,5)$, JOSÉ GUILHERME \\ DE FREITAS $\left({ }^{2,5}\right)$, RUI RIBEIRO DOS SANTOS (3) e JOSÉ CARLOS SABINO $(4,5)$
}

\begin{abstract}
RESUMO
Compararam-se entre si vinte e quatro linhagens e um cultivar comercial de trigo quanto à produção de grāos, componentes da produçāo e resistência às doenças, através de ensaios instalados em diferentes localidades paulistas, em condição de irrigação por aspersāo e de sequeiro. Em casa de vegetação, efetuaram-se estudos de resistência às misturas de raças prevalecentes dos agentes causais da ferrugem-do-colmo e da folha e, em condições de laboratório, estudos da tolerância ao alumínio, em soluçōes nutritivas. As linhagens IAC-156 e IAC-141 salientaram-se quanto à produção de grãos em condição de irrigação por aspersāo e as linhagens IAC-139, |AC-143, IAC-152 e IAC-157 em condiçāo de sequeiro. Em relação
\end{abstract}

(1) Com verba suplementar do Acordo do Trigo entre as Cooperativas de Produtores Rurais do Vale do Paranapanema e a Secretaria da Agricultura, por intermédio do Instituto Agronômico. Recebido para publicação em 29 de março e aceito em 11 de setembro de 1989. (SP).

(2) Seçāo de Arroz e Cereais de Inverno, Instituto Agronômico (IAC), Caixa Postal 28, 13.001 Campinas

(3) Estação Experimental de Monte Alegre do Sul, IAC.

(4) Estação Experimental de Tietê, IAC.

(5) Com bolsa de pesquisa do CNPq. 
à ferrugem-do-colmo (Puccinia graminis f. sp. tritici), as linhagens IAC-142, IAC-144, IAC-145, IAC-146, IAC-148, IAC-149, IAC-150, IAC-152, IAC-153, IAC-157 e IAC-158 e o 'Alondra-S-46' exibiram resistência às duas misturas de raças prevalecentes, em estádio de plântula. As linhagens IAC-143 e IAC-150 apresentaram resistência em estádio de plântula às três misturas de raças prevalecentes de ferrugem-da-folha ( $P$. recondita) em casa de vegetação. Esses genótipos também foram resistentes a essa ferrugem em condiçăo de infecção natural no campo, no estádio de planta adulta. As ljnhagens IAC-140, IAC-143, IAC-145, IAC-150 e IAC-153 mostraram-se resistentes ao oídio, em condição de campo. As linhagens IAC-139, IAC-143, IAC-145, IAC-146, IAC-152, IAC-154, IAC-155 e IAC-158 e o cultivar Alondra-S-46 exibiram plantas de porte baixo. A IAC-147 mostrou ser fonte genética do caráter espiga comprida; a IAC-142, de maior número de espiguetas por espiga; IAC-146 e IAC-147, de maior número de grāos por espiga; IAC-146, IAC-147 e IAC-148, de maior número de grāos por espigueta, e IAC-157, de grãos mais pesados. As linhagens IAC-143, IAC-149, IAC-150 e IAC-156 foram as mais tolerantes à toxicidade de $A{ }^{3+}$, porém num grau significativamente menor em relação ao ' $\mathrm{BH}-1146$ '.

Termos de indexação: trigo, melhoramento genético, cultivares, linhagens, produção de gräos, ferrugem-do-colmo e da-folha, toxicidade de alumínio.

\section{INTRODUÇÃO}

Nos primórdios da agricultura, os trigos evoluíram dentro de dois grandes agrupamentos de genes: os de hábito de inverno e os de hábito de primavera, e em um terceiro agrupamento pequeno: os trigos facultativos. Os termos "trigo de inverno" e "trigo de primavera" têm sentido muito mais amplo do que a estação na qual a cultura é conduzida (HANSON et al., 1982).

Os trigos de hábito de inverno são semeados no outono. As plântulas usualmente emergem e perfilham antes do inverno, permanecendo num estádio inativo durante os meses de frio. As plantas iniciam crescimento rápido na primavera e maturam no verão após um crescimento de nove a onze meses. Os trigos de hábito de inverno requerem vernalização (exposição pelo menos de algumas semanas entre 1 e $5^{\circ} \mathrm{C}$ ) antes de mudar do estádio vegetativo para a fase reprodutiva, que inclui o emborrachamento, o espigamento, o florescimento e a formação de grãos (HANSON et al., 1982).

Trigos de primavera, em contraste, têm um ciclo de crescimento contínuo, geralmente de três a seis meses, não apresentando periodo de inatividade; não sobrevivem quando mantidos sob baixas temperaturas. Em áreas de inverno severo, são plantados na primavera depois das últimas geadas.

Os dois grandes agrupamentos de genes possuem outras diferenças. Muitos trigos de invemo carregam resistência para doenças comuns no seu ambiente de cultivo, tais como o oídio, ferrugem linear e septoriose. Alguns deles apresentam grande tolerância à seca em relação aos de primavera. Por outro la- 
do, os de primavera têm melhor resistência à ferrugem-do-colmo e ao carvão. Ambos os agrupamentos carregam genes para alto potencial produtivo, que parece caráter distinto ou, algumas vezes, aditivo, quando foram feitos cruzamentos entre si (HANSON et al., 1982).

O hábito de primavera difere do de invemo por um par de genes dominantes (POEHLMAN, 1959).

A Universidade Estadual de Oregon, EUA, em convênio com o Centro Internacional de Melhoramento de Milho e Trigo (CIMMYT), México, e outras instituiçōes vêm coordenando um programa de melhoramento visando explorar a variabilidade genética dos trigos de inverno e primavera, os quais são cruzados em Oregon e as sementes $F_{1}$, plantadas no México. As sementes em geraçāo $F_{2}$ são distribuidas a dezenas de paises interessados em aproveitar o potencial genético existente nesse material, visando aumentar a produtividade dos trigos de invemo ou primavera, conforme o caso.

O programa de melhoramento genético do trigo no Instituto Agronômico (IAC) tem por finalidade o desenvolvimento de cultivares com maior produtividade, porte semi-anāo, palha forte (resistência ao acamamento), maior fertilidade da espiga, maior perfilhamento, precocidade (100-120 dias), resistência à degrana, resposta à adubação (principalmente nitrogenada), indice de colheita mais alto, adaptação ampla, resistência às doenças, eficiência à absorção e utilização de $P$ e N, melhores qualidades nutritivas e tecnológicas (CAMARGO, 1987).

$O$ Instituto Agronômico introduz anualmente cem populaçōes hibridas de Oregon, provenientes de cruzamentos entre trigos de inverno e de primavera, as quais são selecionadas nas condiçōes paulistas visando à obtenção de linhagens para serem utilizadas como cultivares (SĀO PAULO, 1979-1987). O presente trabalho tem por objetivo avaliar 24 linhagens de trigo obtidas por seleção nessas populaçōes em diferentes regiōes paulistas.

\section{MATERIAL E MÉTODOS}

\subsection{Genealogia dos genótipos estudados}

A genealogia e a relação das vinte e quatro linhagens encontram-se a seguir.

IAC-136 - Yaktana/Norin 10 Brevor//Narino 59/3/Hyslop/4/Ciano/Gallo;

IAC-137 - Nainari/Dijon/Nogel Selection/II 50-18/4/Santa Catalina/5/Kalyansona/Bluebird;

IAC-138 - Sava/Oliva; 
IAC-139 - Aobakomughi/Pavon 76;

IAC-140 - Pumafen/Lilifen//Protor,

IAC-141 e IAC-142 - Hyslop 706/Flicker;

IAC-143 e IAC-144 - Pumafen/Lilifen//Alondra;

IAC-145, IAC-146, IAC-147, IAC-148 e IAC-150 - Backa/Alondra;

IAC-149 - Capitole/Bluetit;

IAC-151 - Pumafen/Lilifen//Bluetit;

IAC-152 - Vilmorin 29*/Vogel 7353//Sparrow;

IAC-153 - Rannaja/Leonardo 13/4/Tezanos Pintos Precoz//IRN 46/Ciano/3/Cris; no/3/Chris;

IAC-154 e IAC-155 - Lilifen/Nadadores 63//Lilifen/Bezostaja/3/Alondra;

IAC-156 - Lilifen*2//2 Dijon/8316/3/Pavon;

IAC-157 - Fundulea 133-67/4/Correcaminos/INIA/3/Tobari 66/Candealfen//Bluebird;

IAC-158 e IAC-159 - Cruzamento desconhecido/3/Chris//Era/1161-6.

Como controle, foi utilizado o cultivar Alondra-S-46, selecionado pelo CIMMYT e introduzido pelo Centro Nacional de Pesquisa de Trigo, EMBRAPA, onde foi submetido a nova seleção.

\subsection{Ensaios conduzidos em diferentes locais paulistas}

Foi utilizado o delineamento estatístico de blocos ao acaso com três repetiçōes por local. Cada ensaio foi constituído de 75 parcelas, cada uma formada cie cinco linhas de $3 \mathrm{~m}$ de comprimento, espaçadas de $0,20 \mathrm{~m}$. Deixou-se uma separação lateral de $0,60 \mathrm{~m}$ entre as parcelas. A semeadura foi feita na base de 80 sementes viáveis por metro de suco, equivalendo a 1.200 por parcela, com uma área útil de colheita de $3 \mathrm{~m}^{2}$.

Em 1983 foi semeado um ensaio no Centro Experimental de Campinas e, em 1984, três experimentos nos seguintes locais: Centro Experimental de Campinas; Fazenda Nossa Senhora da Penha, município de Florinea, e Estação Experimental de Tietê. Em 1985, realizaram-se três ensaios nos locais de 1984, à exceçāo do de Campinas, que foi plantado na Estação Experimental de Monte Alegre do Sul e, em 1986, dois ensaios: um na Fazenda Lagoa, município de Maracaí, e o outro em Tietê

$\mathrm{Na}$ instalação dos ensaios, retiraram-se amostras compostas desses locais, encontrando-se, no quadro 1, os resultados obtidos pela Seção de Fertilidade do Solo e Nutrição de Plantas, IAC. 


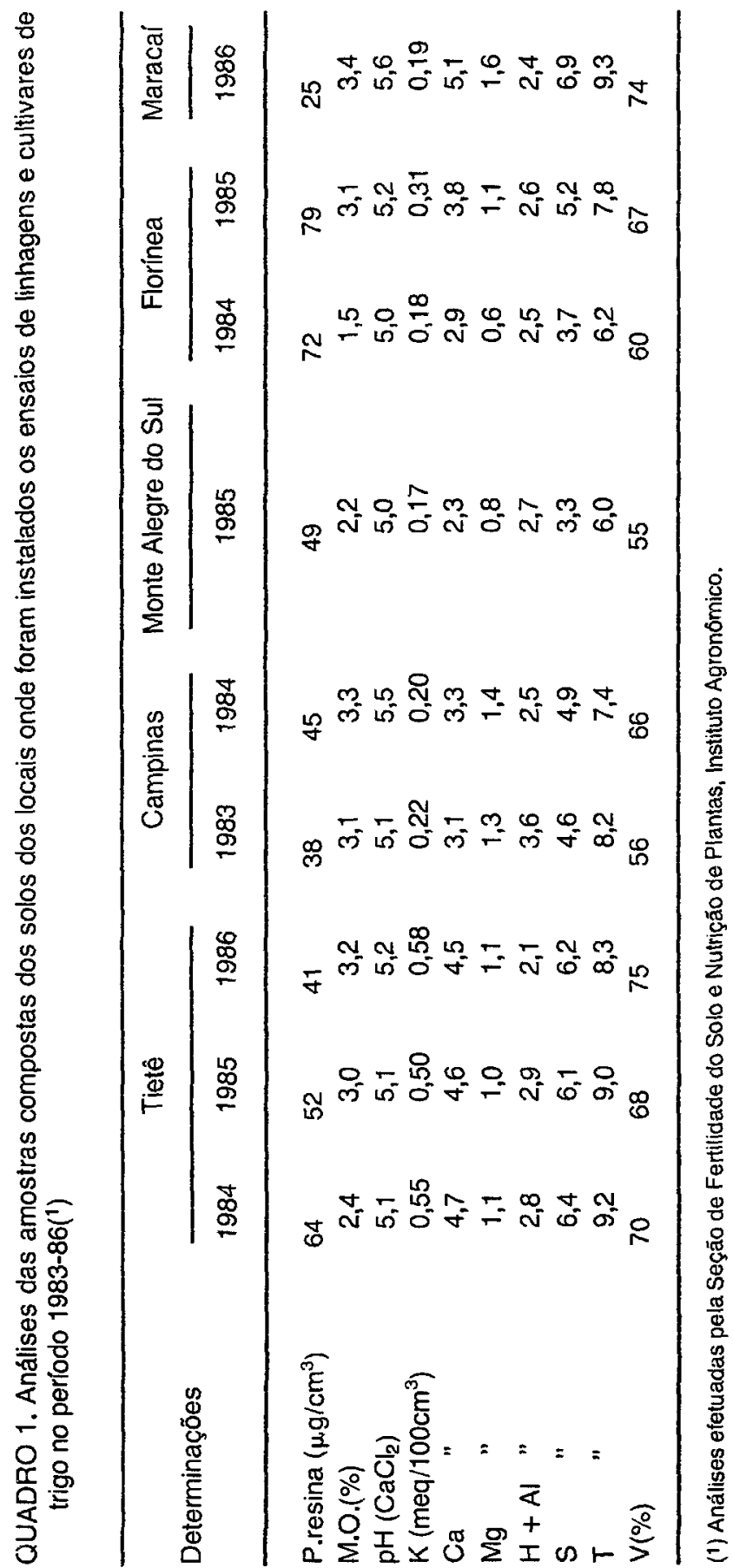


Os experimentos efetuados em Campinas e Monte Alegre do Sul foram irrigados por aspersão, e os demais não foram irrigados.

Foram coletados os seguintes dados:

Ferrugem-do-colmo e da-folha: Avaliada através de observação geral, em cada parcela, no colmo e nas folhas superiores das plantas, no estádio de inicio de maturaçāo, e em condiçōes naturais de infecção, usando-se a escala modificada de Cobb, para a avaliação da resistência no Ensaio Internacional de Ferrugem do Trigo (International Spring Wheat Rust Nursery), empregada por SCHRAM et al. (1974). Essa escala vai de 0 a $99 \%$ de área foliar infectada, complementada pelo tipo de reaçäo: $S=$ suscetivel (uredossoro grande, coalescente, sem necrose e sem clorose); $M S$ = moderadamente suscetível (uredossoro médio); $M=$ intermediário (diversos tipos de reaçāo); $M R=$ moderadamente resistente (uredossoro pequeno); $\mathrm{R}$ = resistente (uredossoro minúsculo, rodeado de áreas necróticas).

Oidio: A avaliação de oídio causado por Erysiphe graminis f. sp. tritici efetuou-se em cada parcela no estádio de planta adulta, em condiçōes naturais de infecçăo, empregando-se uma escala de 0 a $99 \%$ de área infectada, apresentada por MEHTA (1978), onde 0 é considerado imune; 1 a 5\%, resistente; 6 a $25 \%$, moderadamente resistente; 26 a $50 \%$, suscetível, e 51 a $99 \%$, altamente suscetivel.

Ciclo da emergência ao florescimento: Efetuando contagens por parcela individual do número de dias da emergência das plântulas ao pleno florescimento.

Ciclo da emergência à maturação: Efetuando contagens por parcela individual do número de dias da emergência das plântulas à maturaçāo fisiológica.

Plantas acamadas: Considerando a porcentagem de plantas acamadas em cada parcela, por avaliaçāo visual próxima à época de maturação.

Altura das plantas: Medindo no campo, em diferentes pontos de cada parcela, na época de maturação, a distância, em centímetros, do nivel do solo ao ápice da espiga, excluindo as aristas.

Comprimento da espiga: Considerando o comprimento médio, em centimetros, de dez espigas tomadas ao acaso de cada parcela, com exclusão das aristas.

Número de espiguetas: Computando o número médio de espiguetas de dez espigas tomadas ao acaso de cada parcela.

Grāos por espiga: Considerando o número médio de grāos contados em dez espigas colhidas ao acaso de cada parcela.

Grãos por espigueta: Calculando pela divisão do número total de grãos de dez espigas, coletadas ao acaso de cada parcela, pelo número total de suas espiguetas. 
Peso de cem grãos: Considerando o peso, em gramas, de cem grãos tomados ao acaso da produçāo total de cada parcela.

Produção de grãos: Pesando, em gramas, a produção total de grãos de cada parcela, a qual foi transformada para quilograma/hectare.

As características comprimento da espiga, número de espiguetas por espiga, número de grãos por espiga e por espigueta foram somente avaliadas nos ensaios de Campinas (1983 e 1984) e Florínea (1984 e 1985). O peso de cem grāos foi determinado nos mesmos ensaios, com exceção do de Florinea (1985).

\subsection{Ensaios em condição de casa de vegetação e laboratório}

Resistência a raças dos agentes causais de ferrugem-do-colmo e da-folha

As sementes dos genótipos estudados foram remetidas ao Centro Nacional de Pesquisa de Trigo da EMBRAPA, Passo Fundo (RS), para identificaçāo, quanto à resistência em estádio de plântula, em condições de casa de vegetação, a duas misturas de raças de Puccinia graminis f. sp. tritici, agente causal da ferrugem-do-colmo (mistura 1: raças G15, G17, G18, G19, G20 e G21, e mistura 2: raças G22, G23 e G24) e a três misturas de raças de $P$. recondita, agente causal da ferrugem-da-folha (mistura 1: raças B27 e B29; mistura 2: raças B30, B31 e B32, e mistura 3: raças B25, B26, B27, B29, B30, B31, B32 e B33), de ocorrência comum no Brasil (BARCELLOS, 1986, e COELHO, 1986).

Tolerância à toxicidade de aluminio

As linhagens e os cultivares Alondra-S-46 e $\mathrm{BH}-1146$ foram testados para tolerância a $0,2,4,6,8$ e 10mg/litro de $\mathrm{Al}^{3+}$ em soluçōes nutritivas, empregando-se duas repetiçōes, conforme método de CAMARGO \& OLIVEIRA (1981); CAMARGO et al. (1985) e MOORE et al. (1976).

\section{RESULTADOS E DISCUSSĀO}

Os quadrados médios das análises da variância individuais das produçōes médias em quilograma/hectare das linhagens e do cultivar Alondra-S-46, estudados no período 1983-86, em diferentes regiōes paulistas, encontram-se no quadro 2. Os dados mostraram efeitos significativos ao nivel de $1 \%$ para genótipos, em todos os experimentos, com exceção do de 1986 em Tietê, que foi significativo ao nivel de $5 \%$. 


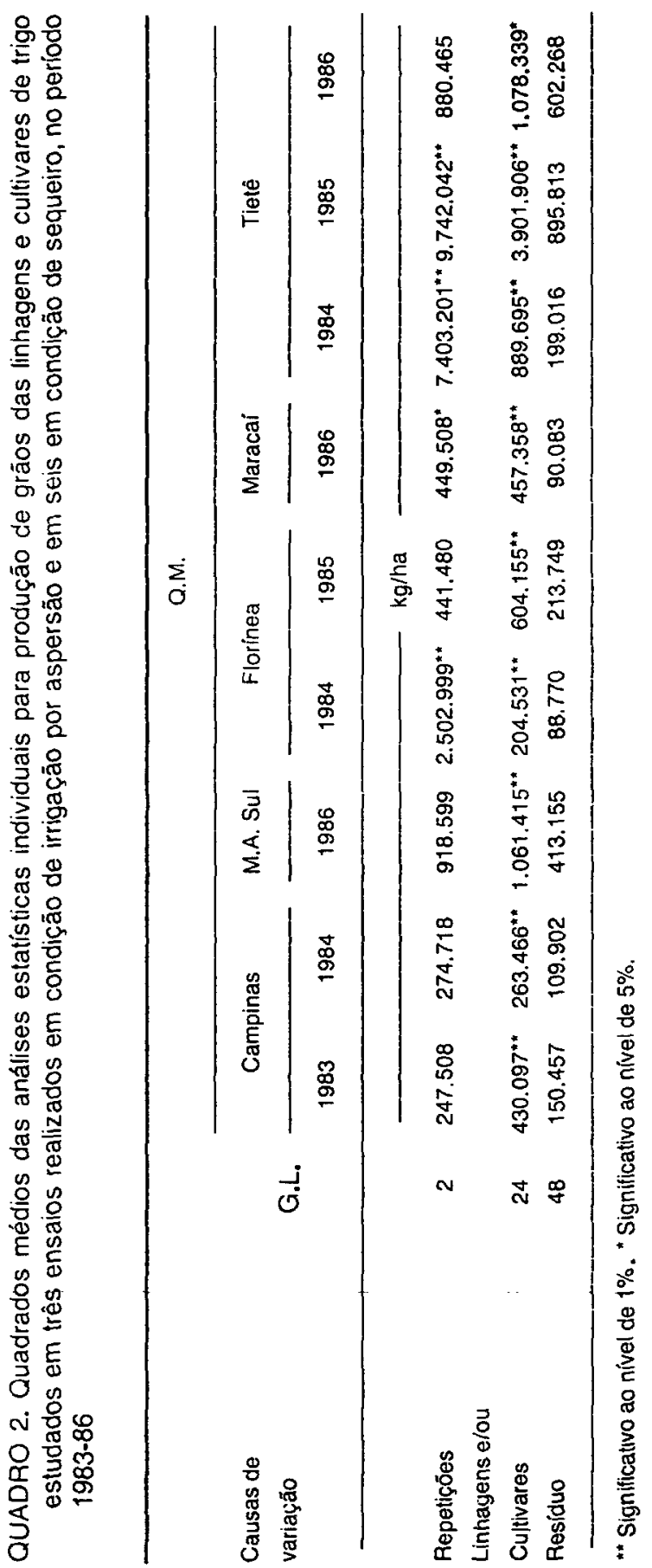


Os quadrados médios da análise da variância conjunta das produçōes médias dos genótipos nos experimentos em condição de irrigaçāo por aspersāo em Campinas (1983 e 1984) e Monte Alegre do Sul (1986) encontram-se no quadro 3. Os resultados exibiram efeitos altamente significativos para experimentos $\mathrm{e}$ interação genótipos $\mathrm{x}$ experimentos, porém os efeitos de genótipos foram nāo-significativos.

Através do teste de Tukey aplicado ao nivel de 5\% para a comparação das médias de produção de grãos dos tratamentos dos ensaios com irrigação por aspersāo - Quadro 4 - verificou-se, no de 1983 em Campinas, que apenas a linhagem IAC-150, que produziu $2.615 \mathrm{~kg} / \mathrm{ha}$, diferiu significativamente do 'AlondraS-46', com 1.333kg/ha. Destacaram-se também, quanto à produçāo de grãos, as linhagens IAC-140, IAC-147 e IAC-148, com produçōes de 2.491, 2.435 e $2.491 \mathrm{~kg} / \mathrm{ha}$ respectivamente. No ensaio de 1984 , em Campinas, a linhagem IAC-143 foi a mais produtiva, com $2.486 \mathrm{~kg} / \mathrm{ha}$, somente diferindo, porém, da menos produtiva, IAC-159, com $1.420 \mathrm{~kg} / \mathrm{ha}$. No ensaio de Monte Alegre do Sul, as linhagens IAC-139 e IAC-151 exibiram as maiores produçōes de grãos, $4.022 \mathrm{e}$ $4.012 \mathrm{~kg} / \mathrm{ha}$ respectivamente, porém somente diferiram da IAC-147, com $1.682 \mathrm{~kg} / \mathrm{ha}$. Considerando-se a média do conjunto dos experimentos conduzidos em condição de irrigação por aspersão, as linhagens IAC-156 e IAC-141 produziram, respectivamente, 2.709 e $2.606 \mathrm{~kg} / \mathrm{ha}$, enquanto 'Alondra-S-46' produziu $2.414 \mathrm{~kg} / \mathrm{ha}$; contudo, não foram observadas diferenças significativas entre os tratamentos.

Os quadrados médios da análise da variância conjunta das produçōes médias de grãos dos genótipos dos ensaios em condição de sequeiro, na região do Vale do Paranapanema, em Florinea (1984 e 1985) e em Maracai (1986), encontram-se no quadro 3 . Os dados mostraram efeitos altamente significativos para experimentos e interação genótipos $x$ experimentos e não-significativos para genótipos.

As produçōes médias de grāos dos genótipos dos ensaios da região do Vale do Paranapanema em 1984-86 encontram-se no quadro 5. No de Florinea, em 1984, a linhagem IAC-141 mostrou a maior produçāo de grãos (1.785kg/ha), diferincio ao nível de $5 \%$, porém, apenas das linhagens IAC-152 e IAC-159, com prođuçōes de 680 e $770 \mathrm{~kg} / \mathrm{ha}$ respectivamente. Em 1985, os genótipos mais produtivos foram IAC-139 (3.733kg/ha), Alondra-S-46 $(3.549 \mathrm{~kg} / \mathrm{ha}), \quad$ IAC-141 $(3.450 \mathrm{~kg} / \mathrm{ha})$ e IAC-138 (3.440 kg/ha), que somente diferiram da linhagem menos prođutiva, IAC-154 (1.840kg/ha). No ensaio de Maracai, a linhagem IAC-142 $(2.044 \mathrm{~kg} / \mathrm{ha})$ apresentou a maior produção de grãos, diferindo do cultivar Alondra-S-46 $(910 \mathrm{~kg} / \mathrm{ha})$. Nesse experimento, destacaram-se também as linhagens IAC-150 (1.751 kg/ha), IAC-141 (1.750kg/ha), IAC-148 (1.730kg/ha), IAC-156 $(1.722 \mathrm{~kg} / \mathrm{ha})$ e $\mid A C-139(1.658 \mathrm{~kg} / \mathrm{ha})$. Considerando a média dos três ensaios, instalados na região do Vale do Paranapanema (municípios de Florínea e Maracaí), em condição de sequeiro (Quadro 5), verificou-se não haver diferenças significativas entre os genótipos estudados devidio a uma significativa interação genótipo $x$ experimento utilizada como quadrado médio residual no teste de Tukey (Quadro 
3). Nessas condiçōes, destacaram-se quanto à produçāo de grãos as linhagens IAC-141 (2.328kg/ha), IAC-142 (2.141kg/ha) e IAC-139 (2.132kg/ha).

Os quadrados médios da análise da variância conjunta das produçōes médias de grãos em quilograma/hectare dos genótipos estudados nos ensaios instalados em condição de sequeiro, na Estação Experimental de Tietê, no período 1984-86, encontram-se no quadro 3. Os resultados mostraram efeitos altamente significativos para genótipos, experimentos e genótipos $x$ experimentos.

No ensaio de Tietê, em 1984, as linhagens IAC-139 (2.267kg/ha) e IAC$147(2.133 \mathrm{~kg} / \mathrm{ha})$ obtiveram a maior produção de grãos, diferindo das linhagens IAC-140 (689kg/ha), IAC-141 (400kg/ha), IAC-142 (100kg/ha) e IAC-156 $(445 \mathrm{~kg} / \mathrm{ha})$, que foram as menos produtivas, devido à ocorrência de encharcamento no solo durante os seus períodos de florescimento (Quadro 5). Em 1985, a IAC-139 mostrou a maior produção $(6.667 \mathrm{~kg} / \mathrm{ha})$, diferindo das linhagens IAC-136, IAC-140, IAC-142, IAC-149, IAC-153 e IAC-156, com produçōes de 3.592, 3.093, $2.773,1.636,3.558$ e $1.521 \mathrm{~kg} / \mathrm{ha}$ respectivamente. No ensaio de 1986 , apesar de nāo haver diferença significativa entre os genótipos estudados, pelo teste de Tukey ao nivel de 5\%, a linhagem IAC-139 (3.499kg/ha) mostrou a maior produção de grãos. Considerando em conjunto os três ensaios conduzidos em Tietê, verificou-se, pela análise da variância, efeitos altamente significativos para genótipo, experimento e interação genótipo $x$ experimento (Quadro 3). Através do teste de Tukey aplicado ao nivel de $5 \%$, observa-se (Quadro 5) que a linhagem IAC139 apresentou a maior produção $(4.144 \mathrm{~kg} / \mathrm{ha})$, diferindo apenas das linhagens IAC-140 (1.873kg/ha), IAC-142 (1.623kg/ha), IAC-149 (2.055kg/ha) e IAC-156 $(1.174 \mathrm{~kg} / \mathrm{ha})$.

Analisando-se em conjunto os seis ensaios em condição de sequeiro, verificou-se efeito significativo ao nivel de $5 \%$ para genótipo e significativo ao nivel de $1 \%$ para ensaio e interação genótipo x ensaio (Quadro 5). Pelo teste de Tukey, observou-se que IAC-139 (3.138kg/ha) foi o mais produtivo, diferindo apenas do IAC-149 (1.804kg/ha) e do IAC-156 (1.597kg/ha). Destacaram-se também quanto à produção de grãos as linhagens $\mid A C-143(2.488 \mathrm{~kg} / \mathrm{ha})$, IAC-152 $(2.498 \mathrm{~kg} / \mathrm{ha})$ e IAC-157 (2.664kg/ha).

Os graus médios de infecçāo de ferrugem-do-colmo e da-folha e oídio, nos genótipos, em cada experimento, em 1983-86, encontram-se no quadro 6.

Em relação à ferrugem-da-folha, destacaram-se, quanto à resistência em planta adulta, as linhagens IAC-136, IAC-145, IAC-147 e IAC-148, com reaçōes variando de 0 a 10S. Nas mesmas condiçōes, as linhagens IAC-137, IAC-139, IAC-141, IAC-149, IAC-151, IAC-153, IAC-155, IAC-157 e IAC-158 foram suscetiveis à ferrugem-da-folha, exibindo, em pelo menos um dos experimentos, um grau de infecção variando entre 40 e 80S. As linhagens IAC-139, IAC-152 e IAC-157, em conóiçāo de sequeiro, e IAC-141, IAC-144 e IAC-151, em condição de irrigação por aspersão, que se apresentaram entre as mais produtivas, mostraram-se sensiveis à ferrugem-da-folha, sugerindo, portanto, a necessidade de incorporar, nesses genótipọs, resistência genética ao agente causal dessa moléstia. 


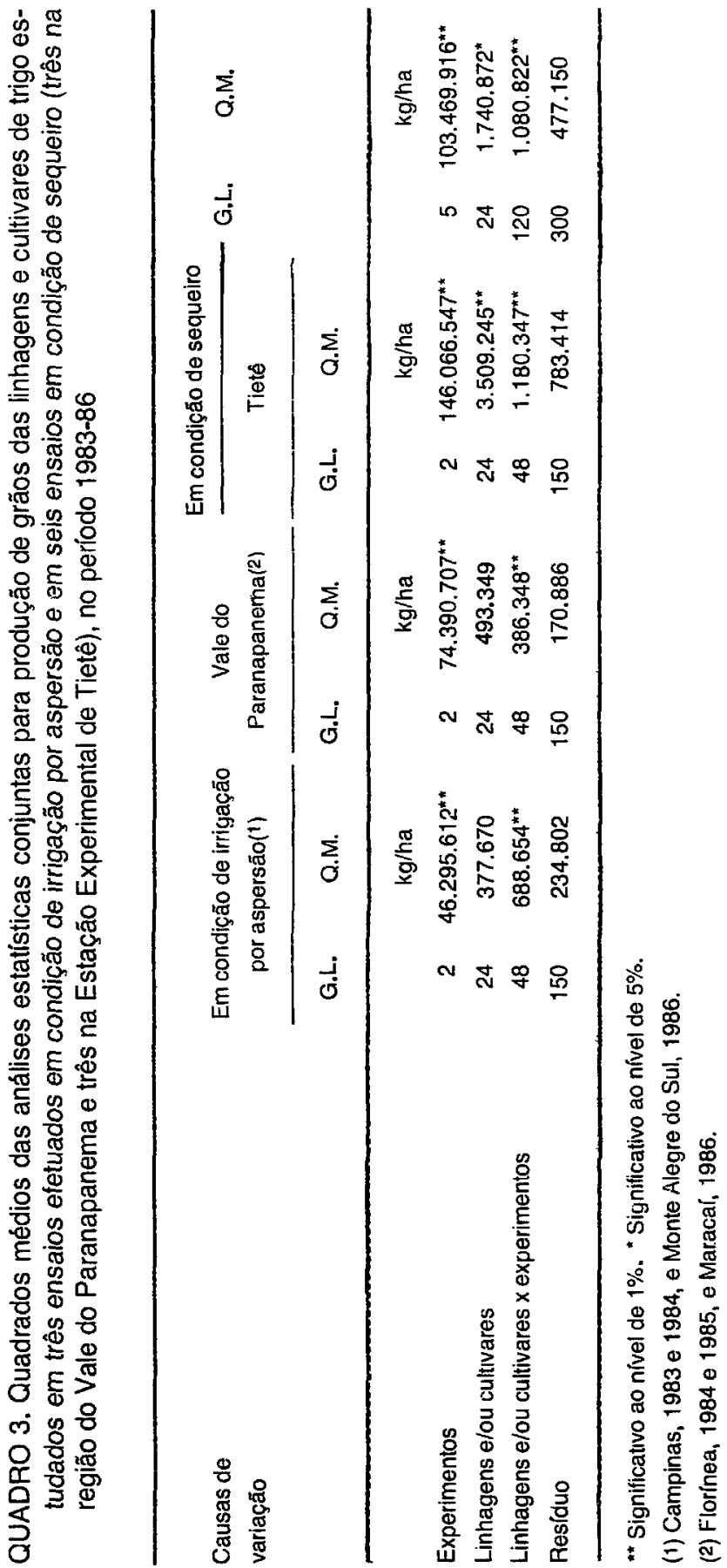




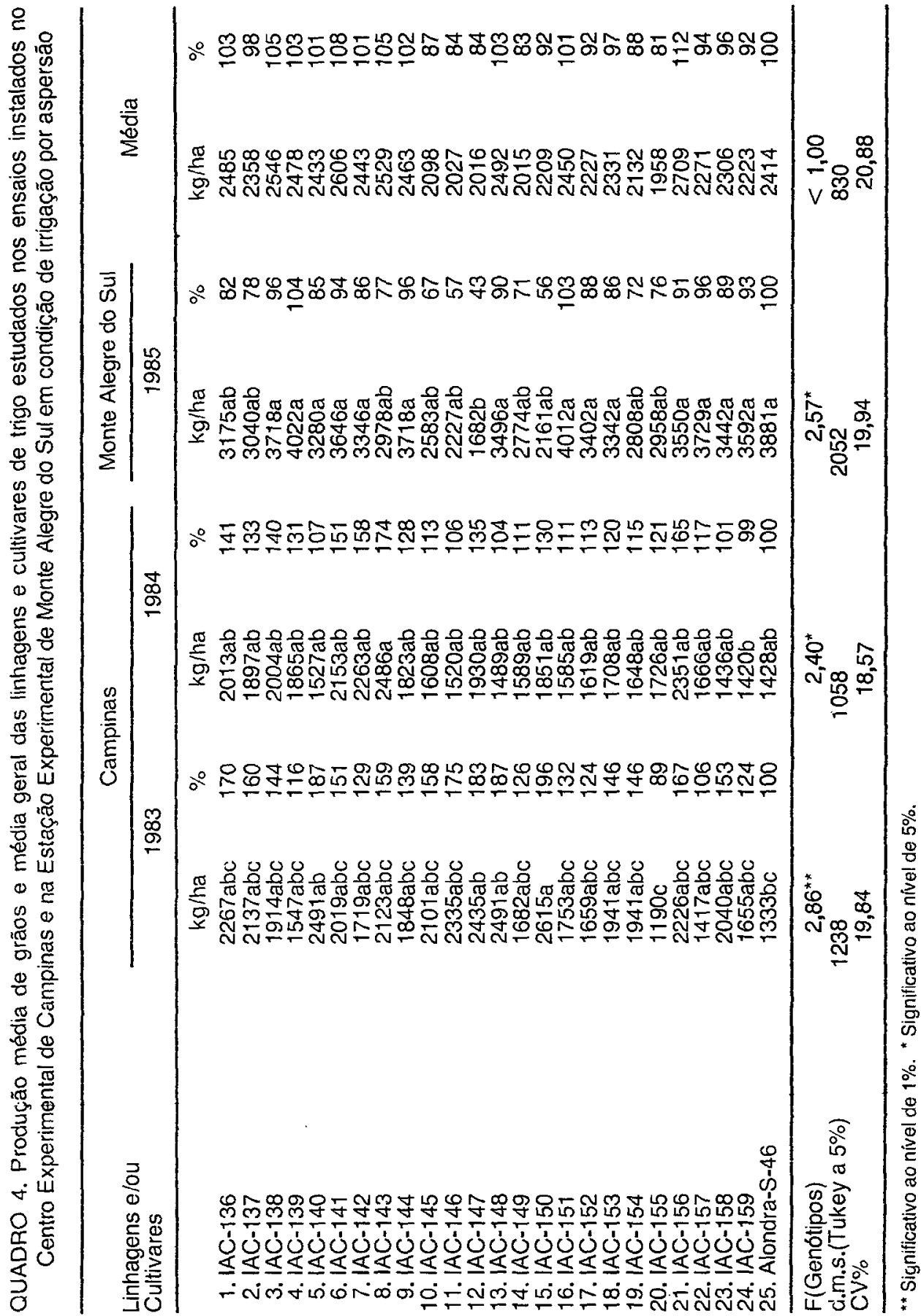




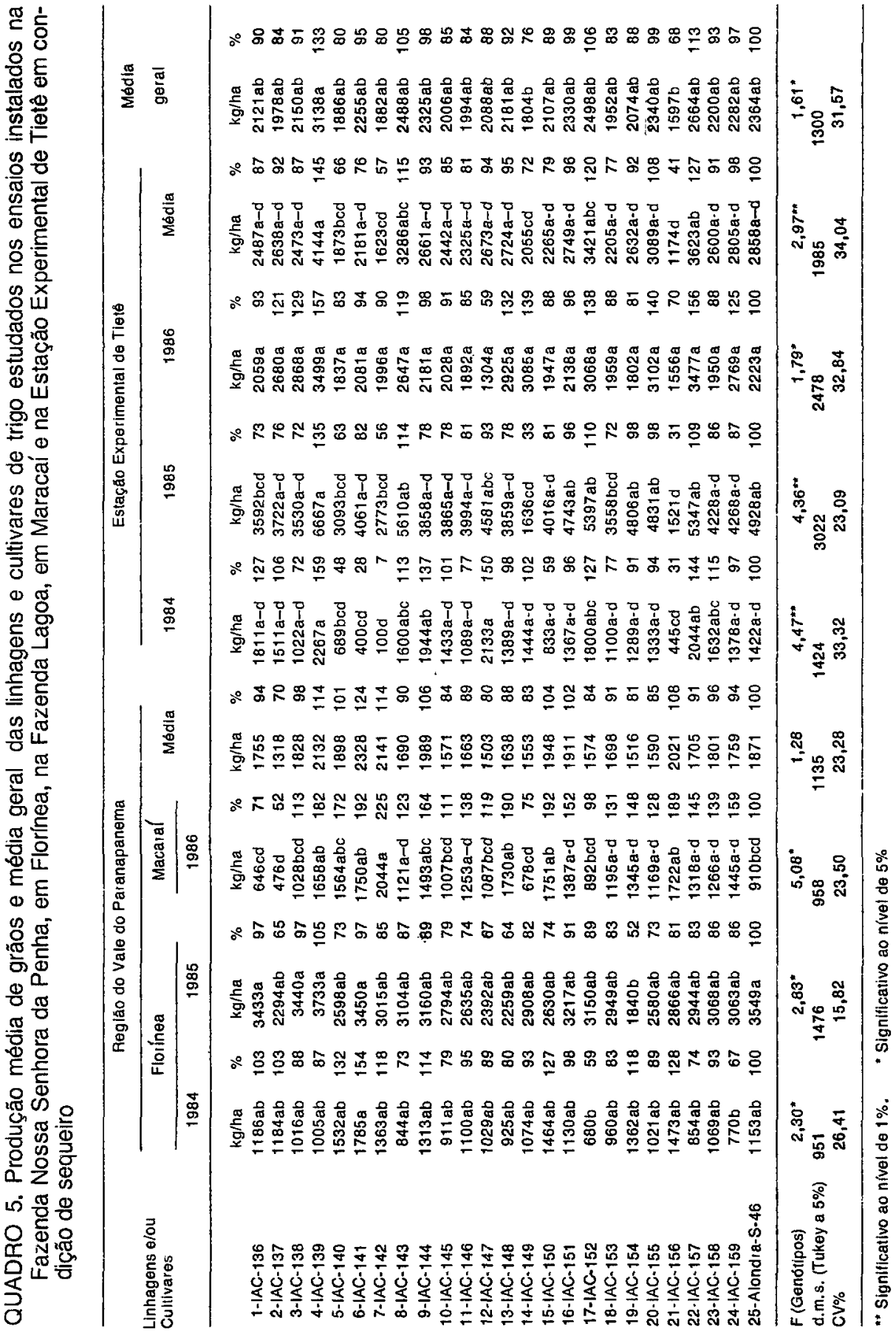




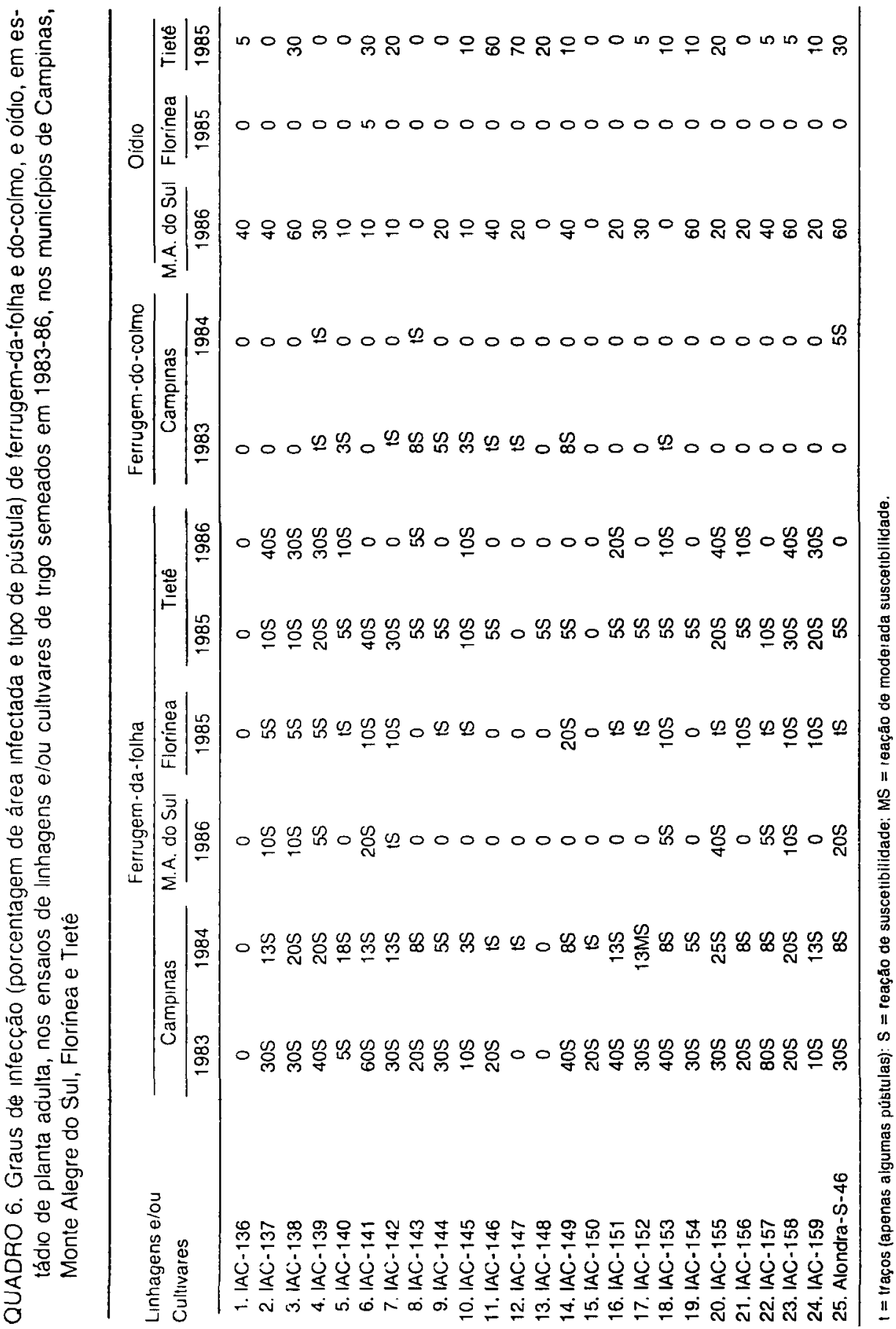


No período estudacio, não houve ocorrência de condições naturais favoráveis para infecção do agente causal da ferrugem-do-colmo. Somente nos ensaios de Campinas (1983 e 1984), houve pequena incidência dessa ferrugem. O cultivar Alondra-S-46 e as linhagens IAC-143 e IAC-149 exibiram reações médias, variando entre 5 e $8 \mathrm{~S}$, sendo esta a maior verificada nos ensaios.

Em relação ao oídio, destacaram-se, quanto à resistência em planta aduita, as linhagens IAC-140, IAC-143, IAC-145, IAC-150 e IAC-153, com graus de infecção entre 0 e 10. IAC-138, IAC-146, IAC-147, IAC-154 e IAC-158 e o cultivar Alondra-S-46 mostraram-se altamente suscetiveis.

As reações das linhagens e do cultivar Alondra-S-46 (estádio de plântula) a Puccinia graminis f. sp. tritici e P. recondita, em casa de vegetação, encontram-se no quadro 7. As linhagens IAC-142, IAC-144, IAC-145, IAC-146, IAC-148, IAC-149, IAC-150, IAC-152, IAC-153, IAC-157 e IAC-158 e o 'Alondra-S-46' foram resistentes às duas misturas de raças prevalecentes do agente causal da ferrugem-do-colmo, em condiçōes de casa de vegetação, constituindo fontes genéticas de valor ao programa de melhoramento do trigo no Instituto Agronômico. As linhagens IAC-143 e IAC-150 mostraram-se resistentes às três misturas de raças prevalecentes do agente causal da ferrugem-da-folha, em estádio de plântula, e exibiram um grau máximo de infeç̧ão em condições de campo igual a 20S, constituindo, portanto, germoplasmas de valor ao programa de melhoramento genético. As linhagens IAC-142, IAC-144, IAC-145, IAC-146, IAC-148 e IAC-157 e 'Alondra-S-46' foram resistentes às misturas de raças 1 e 2 , porém exibiram plântulas segregando entre as reações 0;e4 quando testadas para a mistura de raças 3 , da ferrugem-da-folha. Essas linhagens mostraram um grau máximo de infecção, em condiçōes naturais, em estádio de planta adulta, variando entre 5 e $30 S$, com exceção da IAC-157, que apresentou uma reação de 80 S. Isso sugere que a raça a qual a linhagem IAC-157 é suscetivel foi a prevalecente nas condiçōes estudadas. As linhagens IAC-136 e IAC-147 apresentaram-se como as mais resistentes à ferrugem-da-folha em condição de campo com reaçōes máximas de 0 e tS respectivamente, porém foram somente testadas às misturas de raças 1 e 2 , da ferrugem-da-folha, tendo IAC-136 se mostrado segregante para a mistura de raças $1 \mathrm{e}$ resistente à mistura de raças 2 , e a $\mid A C-147$, resistente às duas misturas de raças para as quais foi testada. Ambas poderiam ser boas fontes de resistência à ferrugem-da-folha, desde que fosse confirmado uma possivel reação de resistência à mistura de raças 3 .

Os quadrados médios das análises da variância conjuntas para a altura da planta, ciclo da emergência ao florescimento e da emergência à maturação, comprimento da espiga, número de espiguetas por espiga, número de grãos por espiga e por espigueta e peso cie cem grãos dos genótipos estudados, em 1983-86, encontram-se no quadro 8. Os resultados mostraram, para todas as características consideradas, efeitos altamente significativos para genótipos, experimentos e interação genótipos $x$ experimentos. 
QUADRO 7. Reações das linhagens e cultivares de trigo (estádio de plântula) às misturas de raças de Puccınia graminıs $\mathrm{f}$. sp. tritıcı e $P$. $r \in$ condita em condições controladas de casa de vegetação, do Centro Nacional de Pesquisa de Trigo (EMBRAPA), Passo Fundo, RS

\begin{tabular}{llll}
\hline Linhagens e/ou & \multicolumn{2}{c}{ Raças de P.graminis tritici } & Raças de P. recondita \\
\cline { 2 - 4 } Cultivares & $\begin{array}{lll}\mathrm{G} 15+\mathrm{G} 17+\mathrm{G} 18+\mathrm{G} 22+\mathrm{G} 23+\mathrm{G} 19+\mathrm{G} 20+\mathrm{G} 21+\mathrm{G} 24 \\
+\mathrm{G} 27+\mathrm{B} 29\end{array}$ & $\begin{array}{ccc}\mathrm{B} 30+\mathrm{B} 31+\mathrm{B} 25+\mathrm{B} 26+\mathrm{B} 27+ \\
+\mathrm{B} 32\end{array}$ & $\begin{array}{c}\mathrm{B} 29+\mathrm{B} 30+\mathrm{B} 31+ \\
+\mathrm{B} 32+\mathrm{B} 33\end{array}$
\end{tabular}

\begin{tabular}{|c|c|c|c|c|c|}
\hline 1. $1 A C-136$ & 3 & 3 & $2 \mathrm{e} 3$ & 2 & \\
\hline 2. $\mid A C-137$ & $2 e 1 P 3$ & 1 & 3,1 & 4,0 & \\
\hline 3. IAC-138 & 2 & $2 e 3$ & 3 & $3 e 2$ & \\
\hline 4. $\mid A C-139$ & 3 & 2 & $4-0 ;, 0$ & $3-0$ & \\
\hline 5. IAC- 140 & 3 & 3 & $3-0$ & $4-2,2$ & \\
\hline 6. IAC-141 & $0 ; 1 \mathrm{e}$ & 1 & $0 ; 1 \mathrm{P} 3-0$ & 0 & $0 ; e 3$ \\
\hline 7. $\mid A C-142$ & 1 & 1 & 0 & 0 & $0 ; 03$ \\
\hline 8. IAC-143 & $0 ; \mathrm{e} 1 \mathrm{P3}$ & 0 & 0 & 0 & $2 P 2$ \\
\hline 9. IAC-144 & $1+$ & 1 & 0 & 0 & $0 ; e 3$ \\
\hline 10. IAC-145 & $0 ; e 1$ & 0 & 0 & 0 & $0 ; e 3$ \\
\hline 11. IAC-146 & 1 & 1 & $0 ;, 1$ & 1 & $0 ;-3$ \\
\hline 12. $\mid A C-147$ & $1+$ & & 1 & 0 & \\
\hline 13. IAC- 148 & 0 & 0 & 0 & 0 & $0 ;, 1 P 4$ \\
\hline 14. $1 \mathrm{AC}-149$ & 1 & 1 & 0 & $0 ;, 1 \mathrm{P3}$ & $0 ;-3$ \\
\hline 15. IAC-150 & 1 & 0 & 0 & 0 & $0 ; e 1$ \\
\hline 16. IAC-151 & 3 & 3 & $3-0$ & 1 & \\
\hline 17. $\mid A C-152$ & 2 & 2 & $3-0 ; 0$ & $3-0$ & \\
\hline 18. IAC-153 & 2 & 2 & $2 / 0 ;-3$ & $3-0$ & \\
\hline 19. IAC-154 & 3 & 4 & $3-0 ; 0$ & 2,0 & \\
\hline 20. IAC-155 & 3 & 4 & 4,0 & $3-0 ; 0$ & \\
\hline 21. IAC-156 & 3 & 3 & $3-0$ & $3-0$ & \\
\hline 22. $\mid A C-157$ & $0 ; e 1$ & 0 & 0 & 0 & 0;e3 \\
\hline 23. IAC-158 & $0 ; 01$ & 2 & $3-1$ & $3-0$ & \\
\hline 24. IAC-159 & 3 & 3 & $3 e 2$ & $2,2 \mathrm{e} 3$ & \\
\hline 25. Alondra-S-46 & 1 & 1 & 1 & 1 & $0 ; e 3$ \\
\hline
\end{tabular}

$0 ; 1,1+, 1-, 2=$ resistente; 3 e $4=$ suscetivel; $P=$ planta; $1 P 3=$ uma planta com reação; $3_{1}-=$ reação variável entre as notas que antecedem e sucedem o hiffen; a vírgula significa segregaçăo ou mistura de sementes; $1 \mathrm{P} 3-0 ;=$ uma planta com reação variável entre 3 e $0 ; /=$ avaliaçōes distintas.

As alturas médias das plantas dios genótipos de trigo estudados em cada um dos nove ensaios no período 1983-86 acham-se no quadro 9. Considerando-se a altura média dos experimentos, as linhagens IAC-139, IAC-143, IAC-145, IAC-146, IAC-152, IAC-154, IAC-155 e IAC-158 mostraram as plantas 
mais baixas, não diferindo do 'Alondra-S-46', com exceçāo da linhagem IAC-155, que foi mais baixa. Esses germoplasmas também exibiram menor porcentagem de plantas acamadas, fazendo exceção a linhagem IAC-158, estando, portanto, entre aqueles com potencial de cultivo em conciçāo de irrigação por aspersão. As linhagens IAC-149, IAC-157, IAC-158 e IAC-159 apresentaram-se com uma porcentagem média de plantas acamadas variando entre 19 e 29, o que foi associado a um porte de planta de médio para alto - Quadro 10.

Os ciclos médios, em dias, da emergência ao florescimento dos genótipos estudados em cadia um de oito ensaios do período encontram-se no quadro 11. Considerando-se o ciclo médio de todos os ensaios, as linhagens IAC-140, IAC-141, IAC-142, IAC-146, IAC-154 e IAC-156 foram as mais tardias para florescer, diferindo significativamente do 'Alondra-S-46' (70 dias).

As linhagens IAC-137, IAC-140, IAC-141, IAC-142, IAC-154 e IAC-156 foram consideradas de ciclo tardio por exibirem um ciclo da emergência à maturação superior a 120 dias e estatisticamente diferentes do 'Alondra-S-46'. Esse cultivar e as demais linhagens mostraram um ciclo de 110 a 120 dias, sendo considerados de ciclo médio. Não foram detectados germoplasmas de ciclo precoce, 100-110 dias, altamente desejáveis para cultivo comercial no Estado de São Paulo - Quadro 12.

A linhagem IAC-147 mostrou as espigas mais compridas, diferindo estatisticamente das outras, com exceção da IAC-143, IAC-150 e IAC-152, constituindo-se numa boa fonte genética, para aumentar esta caracteristica no programa de melhoramento - Quadro 13.

Em relação ao número de espiguetas por espiga, a linhagem IAC-142 apresentou o maior valor utilizando a média de quatro ensaios considerados, diferindo significativamente ao nivel de $5 \%$, pelo teste de Tukey, apenas das linhagens IAC-139, IAC-148, IAC-153, IAC-158 e IAC-159 - Quadro 14.

As linhagens IAC-146 e IAC-147 apresentaram o maior número de grãos por espiga. 'IAC-147' diferiu das linhagens IAC-149, IAC-152, IAC-153, IAC-157, IAC-158 e IAC-159, e a IAC-146, somente das linhagens IAC-152 e IAC-157: Quadro 15. Essas mesmas linhagens, IAC-146 e IAC-147, acrescidas da IAC-148, exibiram o maior número de grãos por espigueta, diferindo somente da IAC-142 e da IAC-152. A IAC-146 também apresentou-se significativamente superior à IAC-149 - Quadro 16. Esses germoplasmas foram considerados de grande valor como fonte genética visando ao aumento do número de grãos por espiga e por espigueta, caracteristicas que requerem melhoramento na maioria dos cultivares atualmente recomendados para as diferentes regiōes triticolas brasileiras.

A linhagem IAC-157 apresentou os grãos mais pesados, considerando a média de três experimentos (Campinas, 1983 e 1984, e Florínea, 1984), diferindo, porém, somente dos genótipos IAC-138, IAC-158 e IAC-159 - Quadro 17. 


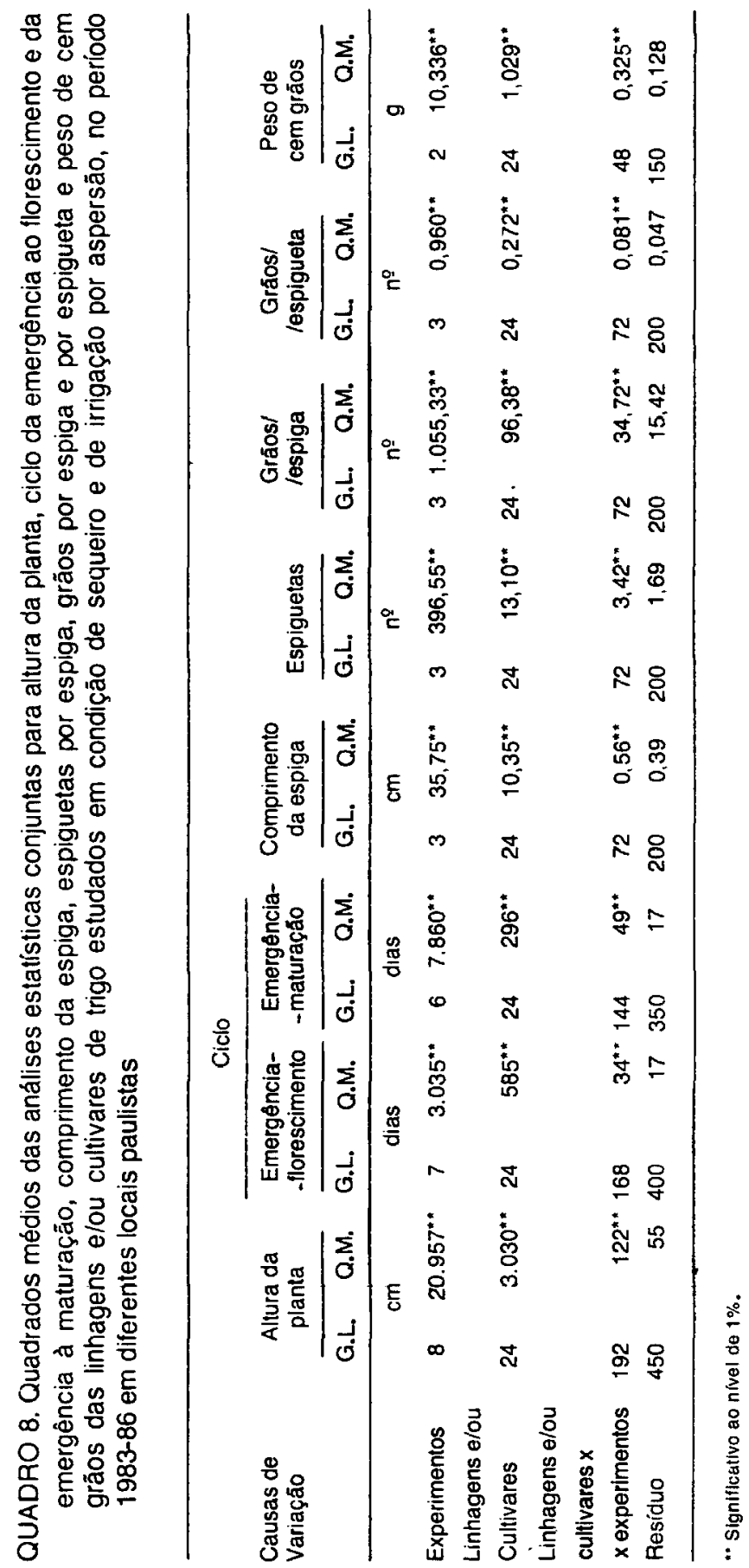




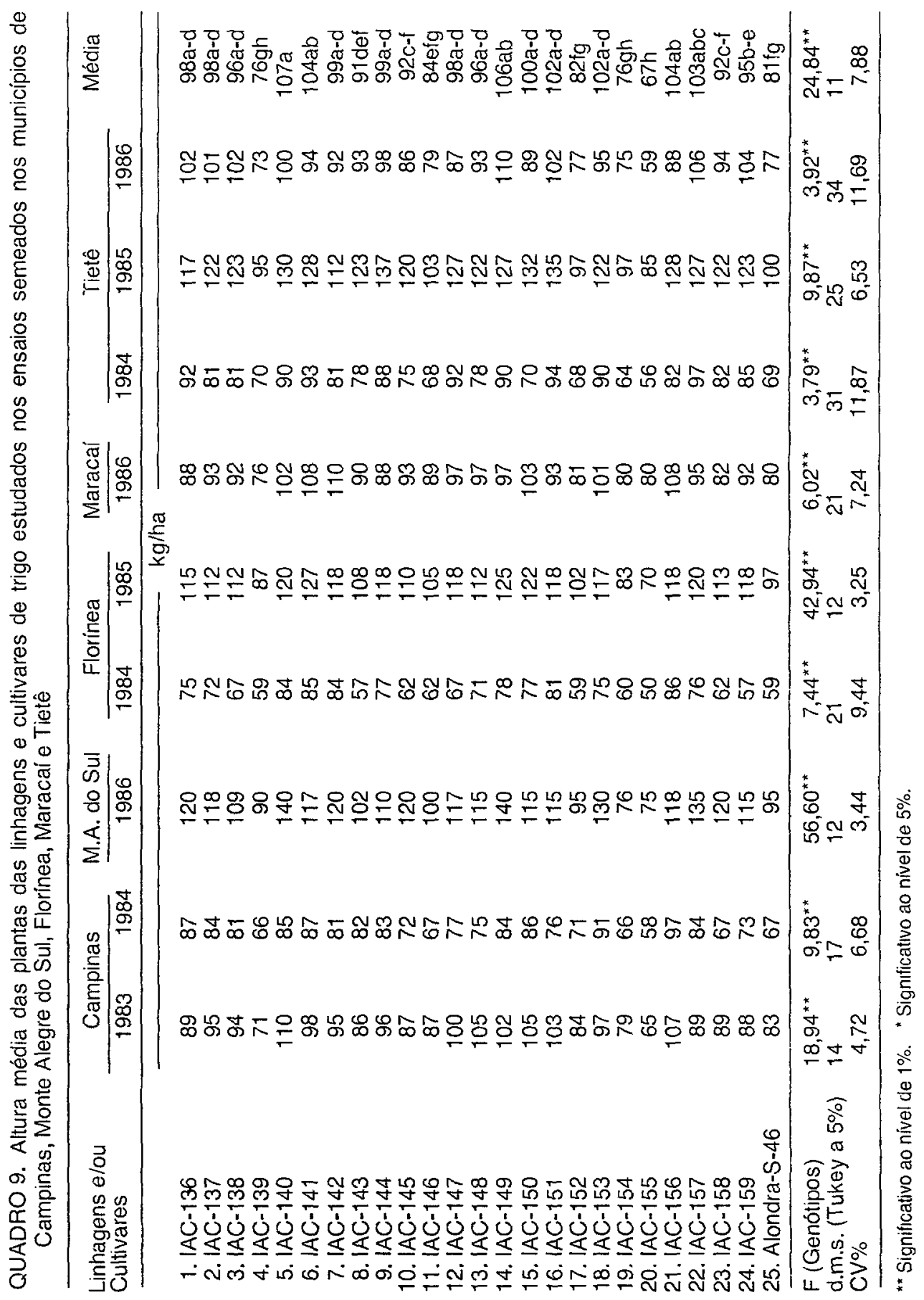




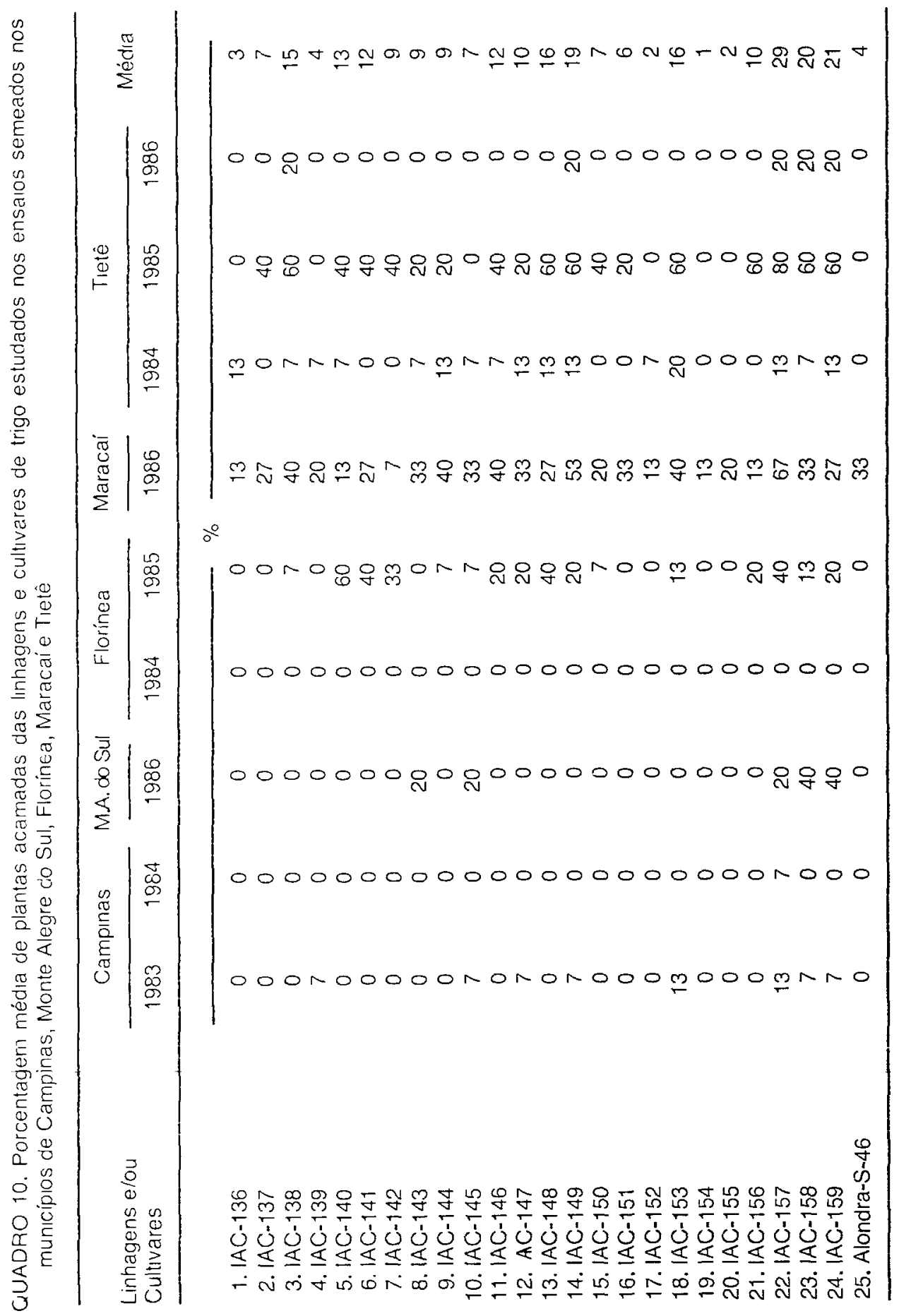




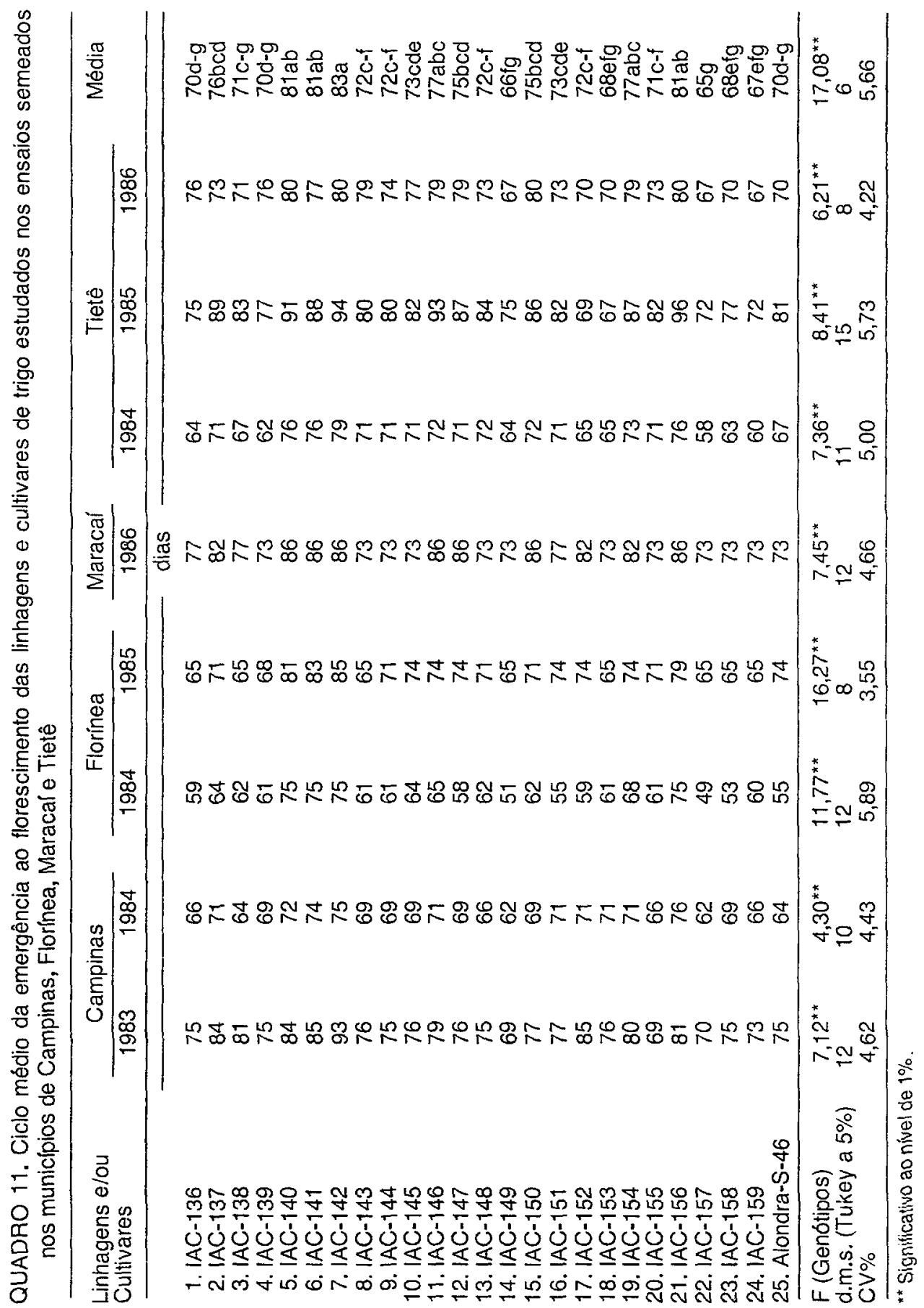




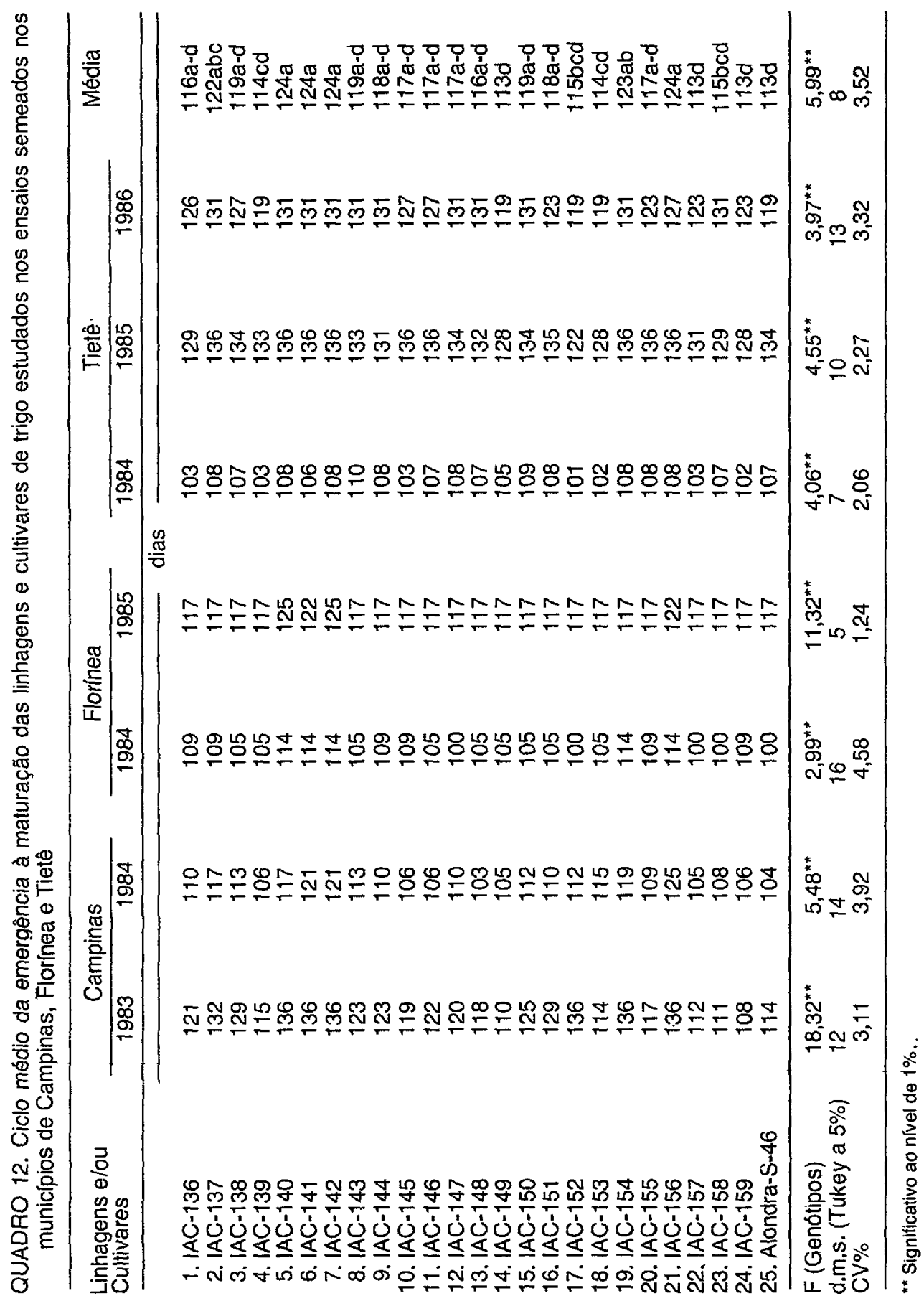


QUADRO 13. Comprimento médio das espigas das linhagens e cultivares de trigo estudados nos ensaios semeados nos municípios de Campinas e Florínea

\begin{tabular}{|c|c|c|c|c|c|}
\hline \multirow{2}{*}{$\begin{array}{l}\text { Linhagens e/ou } \\
\text { Cultivares }\end{array}$} & \multicolumn{2}{|c|}{ Campinas } & \multicolumn{2}{|c|}{ Florínea } & \multirow{2}{*}{ Média } \\
\hline & 1983 & 1984 & 1984 & 1985 & \\
\hline & & & $\mathrm{cm}$ & & \\
\hline 1. IAC-136 & 9,3 & 8,5 & 7,8 & 8,4 & $8,5 c-9$ \\
\hline 2. IAC-137 & 8,9 & 8,1 & 7,8 & 8,9 & $8,4 c-h$ \\
\hline 3. IAC-138 & 7,8 & 6,9 & 6,7 & 7,7 & 7,3hij \\
\hline 4. IAC-139 & 8,3 & 7,0 & 8,1 & 7,9 & $7,8 f-i$ \\
\hline 5. IAC-140 & 8,0 & 6,5 & 7,6 & 8,7 & $7,7 f-i$ \\
\hline 6. IAC-141 & 7,8 & 6,9 & 6,9 & 8,3 & $7,5 g-j$ \\
\hline 7. IAC-142 & 7,5 & 6,8 & 6,9 & 7,8 & 7,3hij \\
\hline 8. IAC-143 & 9,8 & 8,5 & 8,8 & 9,6 & $9,2 a-d$ \\
\hline 9. IAC-144 & 9,1 & 7,1 & 7,0 & 8,4 & $7,9 e-i$ \\
\hline 10. IAC-145 & 9,5 & 8,0 & 7,6 & 9,5 & $8,7 b-t$ \\
\hline 11. IAC-146 & 8,5 & 6,9 & 6,8 & 8,5 & $7,7 f-i$ \\
\hline 12. $\mid A C-147$ & 11,1 & 9,3 & 9,5 & 11,1 & $10,3 a$ \\
\hline 13. IAC-148 & 9,1 & 7,4 & 7,5 & 9,5 & $8,4 c-h$ \\
\hline 14. IAC- 149 & 8,8 & 8,5 & 7,9 & 8,8 & $8,5 c-g$ \\
\hline 15. IAC- 150 & 10,8 & 9,5 & 9,1 & 9,5 & $9,7 a b$ \\
\hline 16. $\mid A C-151$ & 8,9 & 6,9 & 7,9 & 8,5 & $8,1 d-h$ \\
\hline 17. IAC- 152 & 10,9 & 8,5 & 8,2 & 9,4 & $9,3 a b c$ \\
\hline 18. IAC-153 & 8,1 & 7,6 & 6,7 & 7,4 & $7,5 g-j$ \\
\hline 19. IAC-154 & 8,7 & 6,1 & 7,0 & 8,4 & $7,6 f-j$ \\
\hline 20. IAC-155 & 7,7 & 6,8 & 6,9 & 8,0 & 7,3hij \\
\hline 21. IAC-156 & 8,7 & 7,8 & 7,6 & 8,7 & $8,3 c-9$ \\
\hline 22. $\mid A C-157$ & 7,7 & 6,3 & 6,2 & 6,9 & $6,8 i j$ \\
\hline 23. IAC-158 & 7,2 & 6,1 & 6,2 & 6,6 & $6,5 j$ \\
\hline 24. IAC-159 & 8,1 & 6,0 & 6,2 & 7,2 & $6,9 \mathrm{ij}$ \\
\hline 25. Alondra-S-46 & 9,9 & 7,8 & 8,8 & 9,4 & $9,0 b-e$ \\
\hline $\mathrm{F}$ (Genótipos) & $7,25^{\star *}$ & $14,67^{* *}$ & $4,57^{* \star}$ & $8,42^{* *}$ & $18,49^{* *}$ \\
\hline d.m.s. (Tukey a 5\%) & 2,2 & 1,4 & 2,2 & 1,9 & 1,1 \\
\hline CV\% & 7,87 & 6,19 & 9,14 & 7,06 & 7,71 \\
\hline
\end{tabular}

** Significativo ao nivel de $1 \%$.

O comprimento médio das raízes das linhagens e do cultivar Alondra-S46, medidos após 72 horas de crescimento nas soluçōes nutritivas completas, que se seguiu de 48 horas de crescimento nas soluçōes de tratamento contendo seis diferentes concentraçōes de alumínio, encontram-se no quadro 18. Considerando $2 \mathrm{mg} /$ litro de $\mathrm{Al}^{3+}$, pode-se verificar que as linhagens IAC-136, IAC-137, IAC-138, IAC-140, IAC-141, IAC-142, IAC-144, IAC-146, IAC-147, IAC-148, IAC-152, IAC-157, IAC-158 e IAC-159 foram sensiveis a essa concentraçāo, e as demais, tolerantes. 
QUADRO 14. Número médio de espiguetas das linhagens e cultivares de trigo estudados nos ensaios semeados nos municípios de Campinas e Florínea

\begin{tabular}{|c|c|c|c|c|c|}
\hline \multirow{2}{*}{$\begin{array}{l}\text { Linhagens e/ou } \\
\text { Cultivares }\end{array}$} & \multicolumn{2}{|c|}{ Campinas } & \multicolumn{2}{|c|}{ Florinea } & \multirow{2}{*}{ Média } \\
\hline & 1983 & 1984 & 1984 & 1985 & \\
\hline & & & $n^{0}$ & & - \\
\hline 1. $\mid A C-136$ & 19,7 & 15,0 & 16,4 & 19,4 & $17,6 a b c$ \\
\hline 2. $I A C-137$ & 19,4 & 17,4 & 15,1 & 18,1 & $17,5 a b c$ \\
\hline 3. IAC-138 & 20,2 & 15,7 & 16,2 & 20,0 & $18,1 \mathrm{abc}$ \\
\hline 4. IAC-139 & 17,7 & 12,3 & 15,8 & 16,3 & $15,5 \mathrm{c}$ \\
\hline 5. IAC-140 & 20,5 & 12,7 & 17,6 & 18,6 & $17,4 a b c$ \\
\hline 6. $\mid A C-141$ & 20,4 & 16,3 & 17,8 & 20,0 & $18,6 a b$ \\
\hline 7. IAC-142 & 20,3 & 18,6 & 17,5 & 20,2 & $19,2 a$ \\
\hline 8. $\mid A C-143$ & 19,1 & 13,3 & 17,1 & 17,5 & $16,8 a b c$ \\
\hline 9. IAC-144 & 19,9 & 14,2 & 16,0 & 18,7 & $17,2 a b c$ \\
\hline 10. $\mid A C-145$ & 19,5 & 13,2 & 15,9 & 18,5 & $16,8 \mathrm{abc}$ \\
\hline 11. IAC-146 & 19,5 & 13,9 & 16,4 & 18,7 & $17,1 a b c$ \\
\hline 12. IAC-147 & 22,0 & 14,8 & 17,0 & 20,8 & $18,7 a b$ \\
\hline 13. $\mid A C-148$ & 18,8 & 13,4 & 14,4 & 18,3 & $16,2 b c$ \\
\hline 14. $\mid A C-149$ & 19,2 & 15,0 & 16,2 & 19,1 & $17,4 a b c$ \\
\hline 15. $\mid A C-150$ & 21,2 & 14,9 & 16,6 & 17,9 & $17,7 a b c$ \\
\hline 16. IAC-151 & 20,0 & 14,8 & 18,8 & 18,7 & $18,1 a b c$ \\
\hline 17. IAC-152 & 23,5 & 15,2 & 15,6 & 19,8 & $18,5 a b$ \\
\hline 18. $\mid A C-153$ & 16,9 & 14,8 & 15,2 & 16,5 & $15,9 b c$ \\
\hline 19. $\mid A C-154$ & 21,3 & 14,2 & 17,8 & 21,6 & $18,7 \mathrm{ab}$ \\
\hline 20. IAC-155 & 17,4 & 14,2 & 17,2 & 19,6 & $17,1 \mathrm{abc}$ \\
\hline 21. IAC-156 & 20,2 & 16,7 & 16,9 & 20,0 & $18,5 a b$ \\
\hline 22. $\mid A C-157$ & 17,8 & 12,7 & 17,0 & 18,3 & $16,4 a b c$ \\
\hline 23. $\mid A C-158$ & 17,1 & 12,8 & 16,4 & 17,3 & $15,9 b c$ \\
\hline 24. IAC-159 & 17,6 & 12,1 & 14,7 & 17,6 & $15,5 \mathrm{c}$ \\
\hline 25. Alondra-S-46 & 20,2 & 14,2 & 17,1 & 18,4 & $17,5 a b c$ \\
\hline F(Genótipos) & $8,30^{* *}$ & $3,66^{\star \star}$ & $3,51^{* \star}$ & $2,84^{\star \star}$ & $3,83^{\star \star}$ \\
\hline d.m.s. (Tukey a $5 \%$ ) & 3,0 & 4,6 & 3,1 & 4,1 & 2,8 \\
\hline CV\% & 4,86 & 9,97 & 5,88 & 6,98 & 7,48 \\
\hline
\end{tabular}

** Significativo ao nivel de $1 \%$.

As linhagens IAC-139 e IAC-151 foram tolerantes a $2 \mathrm{mg} / \mathrm{litro}$ de $\mathrm{A}^{3+}$ na soluçāo tratamento, porém exibiram sensibilidade quando se empregaram soluçōes com 4mg/litro, sendo, portanto, consideradas como moderadamente sensiveis. 
QUADRO 15. Número médio de grãos por espiga das linhagens e cultivares de trigo estudados nos ensaios semeados nos municípios de Campinas e Florinea

\begin{tabular}{|c|c|c|c|c|c|}
\hline \multirow{2}{*}{$\begin{array}{l}\text { Linhagens e/ou } \\
\text { Cultivares }\end{array}$} & \multicolumn{2}{|c|}{ Campinas } & \multicolumn{2}{|c|}{ Florínea } & \multirow{2}{*}{ Média } \\
\hline & 1983 & 1984 & 1984 & 1985 & \\
\hline & & & $n^{\circ}$ & & . \\
\hline 1. $\mid A C-136$ & 41,1 & 36,8 & 30,9 & 37,7 & $36,7 a b c$ \\
\hline 2. $1 A C-137$ & 35,5 & 34,1 & 30,6 & 33,8 & $33,5 a b c$ \\
\hline 3. $\mid A C-138$ & 38,7 & 37,6 & 28,7 & 36,8 & $35,5 a b c$ \\
\hline 4. $I A C-139$ & 38,2 & 28,5 & 34,9 & 29,4 & $32,8 a b c$ \\
\hline 5. $\mid A C-140$ & 45,9 & 25,1 & 35,8 & 34,5 & $35,3 a b c$ \\
\hline 6. $1 A C-141$ & 37,4 & 33,7 & 35,9 & 36,2 & $35,8 a b c$ \\
\hline 7. IAC-142 & 38,3 & 29,2 & 28,4 & 35,7 & $32,9 a b c$ \\
\hline 8. IAC-143 & 37,6 & 33,6 & 34,2 & 34,3 & $34,9 a b c$ \\
\hline 9. IAC-144 & 42,0 & 31,5 & 31,2 & 33,8 & $34,6 a b c$ \\
\hline 10. IAC- 145 & 36,5 & 30,4 & 31,8 & 37,9 & $34,2 a b c$ \\
\hline 11. IAC-146 & 44,1 & 31,7 & 35,9 & 42,7 & $38,6 a b$ \\
\hline 12. IAC- 147 & 42,9 & 35,8 & 35,5 & 43,9 & $39,6 a$ \\
\hline 13. IAC-148 & 39,9 & 31,0 & 30,2 & 40,8 & $35,5 a b c$ \\
\hline 14. IAC-149 & 33,6 & 33,8 & 26,1 & 26,6 & $30,1 b c$ \\
\hline 15. IAC-150 & 42,9 & 33,7 & 31,1 & 32,7 & $35,1 \mathrm{abc}$ \\
\hline 16. IAC-151 & 41,3 & 29,5 & 36,0 & 39,5 & $36,6 a b c$ \\
\hline 17. IAC-152 & 32,5 & 24,4 & 26,7 & 30,8 & $28,6 c$ \\
\hline 18. IAC-153 & 31,2 & 30,1 & 27,4 & 33,3 & $30,5 b c$ \\
\hline 19. IAC-154 & 46,1 & 23,9 & 34,1 & 44,0 & $37,1 a b c$ \\
\hline 20. IAC- 155 & 36,0 & 31,0 & 30,9 & 36,2 & $33,6 a b c$ \\
\hline 21. IAC-156 & 39,5 & 35,9 & 33,5 & 32,1 & $34,9 a b c$ \\
\hline 22. $1 \mathrm{AC}-157$ & 35,9 & 24,7 & 28,5 & 28,5 & $29,4 c$ \\
\hline 23. IAC-158 & 33,5 & 28,6 & 31,2 & 28,9 & $30,6 b c$ \\
\hline 24. IAC-159 & 41,0 & 24,8 & 25,2 & 32,1 & $30,8 b c$ \\
\hline 25. Alondra-S-46 & 42,8 & 28,2 & 35,0 & 35,4 & $35,4 a b c$ \\
\hline F(Genótipos) & $2,91^{* \star}$ & $2,61^{\star *}$ & $1,67^{*}$ & $4,05^{\star \star}$ & $2,78^{* *}$ \\
\hline d.m.s. (Tukey a 5\%) & 13,1 & 13,7 & 14,5 & 12,7 & 8,7 \\
\hline CV\% & 10,61 & 14,20 & 14,36 & 11,47 & 11,52 \\
\hline
\end{tabular}

** Significativo ao nivel de $1 \%$. ${ }^{*}$ Significativo ao nivel de $5 \%$.

As linhagens IAC-145, IAC-153, IAC-154 e IAC-155 e o cultivar Alondra-S-46 foram tolerantes a $4 \mathrm{mg} /$ litro de $\mathrm{Al}^{3+}$, porém demonstraram sensibilidade à presença de $6 \mathrm{mg} /$ litro de $\mathrm{Al}^{3+}$ nas soluções de tratamento. Esses genótipos foram considerados moderadamente tolerantes. 
QUADRO 16. Número médio de grãos por espigueta das linhagens e cultivares de trigo estudados nos ensalos semeados nos municípios de Campinas e Florínea

\begin{tabular}{|c|c|c|c|c|c|}
\hline \multirow{2}{*}{$\begin{array}{l}\text { Linhagens e/ou } \\
\text { Cultivares }\end{array}$} & \multicolumn{2}{|c|}{ Campinas } & \multicolumn{2}{|c|}{ Florínea } & \multirow{2}{*}{ Média } \\
\hline & 1983 & 1984 & 1984 & 1985 & \\
\hline & & & $n^{\circ}$ & & - \\
\hline 1. IAC- 136 & 2,09 & 2,60 & 1,88 & 1,97 & $2,14 a b c$ \\
\hline 2. $\mathrm{IAC}-137$ & 1,83 & 1,93 & 2,03 & 1,83 & $1,91 \mathrm{a}-\mathrm{d}$ \\
\hline 3. $1 A C-138$ & 1,91 & 2,37 & 1,77 & 1,83 & $1,97 a-d$ \\
\hline 4. $\mid A C-139$ & 2,16 & 2,30 & 2,19 & 1,83 & $2,12 a b c$ \\
\hline 5. IAC-140 & 2,24 & 2,00 & 2,02 & 1,83 & $2,02 a b c$ \\
\hline 6. $\mid A C-141$ & 1,83 & 2,03 & 2,02 & 1,83 & $1,93 a-d$ \\
\hline 7. IAC-142 & 1,88 & 1,57 & 1,63 & 1,77 & $1,71 \mathrm{~cd}$ \\
\hline 8. $1 A C-143$ & 1,97 & 2,53 & 1,99 & 2,00 & $2,12 a b c$ \\
\hline 9. IAC-144 & 2,10 & 2,17 & 1,92 & 1,80 & $2,00 a b c$ \\
\hline 10. $\mid A C-145$ & 1,87 & 2,30 & 1,99 & 2,07 & $2,06 a b c$ \\
\hline 11. $\mid A C-146$ & 2,25 & 2,27 & 2,19 & 2,27 & $2,24 a$ \\
\hline 12. $\mid A C-147$ & 1,95 & 2,43 & 2,08 & 2,13 & $2,15 a b$ \\
\hline 13. $\mid A C-148$ & 2,12 & 2,30 & 2,10 & 2,23 & $2,19 a b$ \\
\hline 14. $\mid A C-149$ & 1,76 & 2,23 & 1,60 & 1,57 & $1,79 \mathrm{bcd}$ \\
\hline 15. $1 \mathrm{AC}-150$ & 2,03 & 2,23 & 1,86 & 1,80 & $1,98 a-d$ \\
\hline 16. $\mid A C-151$ & 2,07 & 2,00 & 1,91 & 2,13 & 2,03abc \\
\hline 17. IAC-152 & 1,38 & 1,60 & 1,70 & 1,57 & $1,56 \mathrm{~d}$ \\
\hline 18. $1 A C-153$ & 1,85 & 2,03 & 1,79 & 2,03 & $1,93 a-d$ \\
\hline 19. $\mid \mathrm{AC}-154$ & 2,17 & 1,73 & 1,91 & 2,03 & $1,96 a-d$ \\
\hline 20. IAC-155 & 2,08 & 2,17 & 1,79 & 1,87 & $1,98 a-d$ \\
\hline 21. IAC-156 & 1,96 & 2,17 & 1,98 & 1,60 & $1,93 a-d$ \\
\hline 22. $\mid \mathrm{AC}-157$ & 2,02 & 1,97 & 1,66 & 1,57 & $1,81 a-d$ \\
\hline 23. $\mid A C-158$ & 1,96 & 2,30 & 1,89 & 1,67 & $1,95 a-d$ \\
\hline 24. $1 \mathrm{AC}-159$ & 2,33 & 2,03 & 1,70 & 1,80 & $1,97 a-d$ \\
\hline 25. Alondra-S-46 & 2,10 & 2,00 & 2,04 & 1,93 & $2,02 a b c$ \\
\hline F(Genótipos) & $3,72^{\star \star}$ & $2,86^{* *}$ & $2,00^{*}$ & $3,00^{\star \star}$ & $3,35^{\star \star}$ \\
\hline d.m.s. (Tukey a 5\%) & 0,55 & 0,84 & 0,64 & 0,63 & 0,43 \\
\hline $\mathrm{CV} \%$ & 8,75 & 12,60 & 10,47 & 10,64 & 10,95 \\
\hline
\end{tabular}

* Significativo ao nivel de $1 \%$. "Significativo ao nivel de $5 \%$.

As linhagens IAC-143, IAC-149, IAC-150 e IAC-156 foram sensiveis a $8 \mathrm{mg} /$ litro de $\mathrm{Al}^{3+}$ nas soluçōes de tratamento, porém tolerantes na presença de $6 \mathrm{mg} / \mathrm{litro}$ de $\mathrm{A}^{3+}{ }^{3+}$, sendo, portanto,consideradas as mais tolerantes à toxicidade de $\mathrm{Al}^{3+}$ entre as linhagens selecionadas das populações híbridas oriundas de Oregon, EUA. Em comparação ao cultivar BH-1146, que exibiu crescimento das raizes mesmo quando se adicionaram $10 \mathrm{mg} / \mathrm{litro}$ de $\mathrm{Al}^{3+}$ nas soluções de tratamento, essas linhagens apresentaram um grau de tolerância significativamente menor. 
QUADRO 17. Peso médio de cem grãos das linhagens e cultivares de trigo estudados nos ensaios semeados nos municípios de Campinas e Florínea

\begin{tabular}{|c|c|c|c|c|}
\hline \multirow{2}{*}{$\begin{array}{l}\text { Linhagens e/ou } \\
\text { Cultivares }\end{array}$} & \multicolumn{2}{|c|}{ Campinas } & Florinea & \multirow{2}{*}{ Média } \\
\hline & 1983 & 1984 & 1984 & \\
\hline & & & & \\
\hline 1. $\mid A C-136$ & 3,82 & 5,13 & 4,71 & $4,56 a b$ \\
\hline 2. IAC-137 & 3,48 & 3,97 & 4,52 & $3,99 \mathrm{abc}$ \\
\hline 3. IAC-138 & 3,08 & 4,17 & 3,84 & $3,70 b c$ \\
\hline 4. IAC-139 & 3,31 & 4,57 & 4,27 & $4,05 a b c$ \\
\hline 5. IAC-140 & 3,89 & 4,03 & 3,96 & $3,96 a b c$ \\
\hline 6. IAC-141 & 3,85 & 4,43 & 4,57 & $4,28 \mathrm{ab}$ \\
\hline 7. IAC-142 & 3,76 & 3,50 & 4,66 & $3,97 a b c$ \\
\hline 8. IAC-143 & 3,71 & 5,10 & 4,42 & $4,41 a b$ \\
\hline 9. IAC-144 & 4,27 & 4,57 & 4,48 & $4,44 a b$ \\
\hline 10. IAC-145 & 3,72 & 4,80 & 4,41 & $4,31 a b$ \\
\hline 11. IAC-146 & 3,63 & 4,70 & 4,24 & $4,19 a b c$ \\
\hline 12. $\mid A C-147$ & 3,86 & 5,10 & 4,53 & $4,50 a b$ \\
\hline 13. $\mid A C-148$ & 3,86 & 4,73 & 4,22 & $4,27 a b$ \\
\hline 14. IAC-149 & 3,88 & 4,30 & 4,12 & $4,10 a b c$ \\
\hline 15. IAC-150 & 3,61 & 4,47 & 4,56 & $4,21 a b c$ \\
\hline 16. IAC-151 & 3,94 & 4,67 & 4,21 & $4,27 a b$ \\
\hline 17. IAC-152 & 3,36 & 4,47 & 3,98 & $3,94 a b c$ \\
\hline 18. IAC-153 & 3,89 & 4,43 & 4,84 & $4,39 a b$ \\
\hline 19. IAC-154 & 3,96 & 5,30 & 4,34 & $4,53 \mathrm{ab}$ \\
\hline 20. IAC-155 & 3,29 & 4,47 & 3,86 & $3,87 \mathrm{abc}$ \\
\hline 21. IAC-156 & 3,88 & 3,77 & 4,03 & $3,89 a b c$ \\
\hline 22. IAC-157 & 4,79 & 5,10 & 4,57 & $4,82 a$ \\
\hline 23. IAC-158 & 3,45 & 2,93 & 3,36 & $3,25 \mathrm{c}$ \\
\hline 24. IAC-159 & 3,49 & 3,67 & 3,81 & $3,66 \mathrm{bc}$ \\
\hline 25. Alondra-S-46 & 3,68 & 4,90 & 4,30 & $4,29 a b$ \\
\hline F(Genótipos) & $5,16^{* *}$ & $5,10^{* *}$ & $3,89^{* *}$ & $3,17^{* *}$ \\
\hline d.m.s. (Tukey a 5\%) & 0,83 & 1,40 & 0,96 & 0,97 \\
\hline CV\% & 6,99 & 9,69 & 7,01 & 8,63 \\
\hline
\end{tabular}

** Significativo ao nivel de $1 \%$.

O nivel de tolerância à toxicidade de alumínio em soluçōes nutritivas exibido pelas linhagens provenientes de cruzamentos entre trigos de inverno e de primavera foi bastante inferior aos germoplasmas cultivados no Estado de São Paulo (CAMARGO \& OLIVEIRA, 1981). Isso, porém, parece não ter mostrado grande interferência no comportamento das linhagens nas condiçōes de campo, onde os ensaios foram instalados, pois os solos utilizados apresentaram saturaçāo por bases variando entre 55 e 74\% (Quadro 1). Nessas condiçōes, o efeito nocivo do $\mathrm{Al}^{3+}$ às raízes das plantas sensiveis seria bastante minimizado. 
QUADRO 18. Comprimento médio das raizes das linhagens e cultivares de trigo, medido após 72 horas de crescimento na solução nutritiva completa, que se seguiu de crescimento na solução de tratamento contendo seis concentraçōes de $A^{\beta+}$

\begin{tabular}{|c|c|c|c|c|c|c|}
\hline \multirow{2}{*}{$\begin{array}{l}\text { Linhagens e/ou } \\
\text { Cultivares }\end{array}$} & \multicolumn{6}{|c|}{ Concentração de aluminjo (mg/litro) } \\
\hline & 0 & 2 & 4 & 6 & 8 & 10 \\
\hline & \multicolumn{6}{|c|}{$\mathrm{mm}$} \\
\hline 1. $1 \mathrm{AC}-136$ & 46,0 & 0,0 & 0,0 & 0,0 & 0,0 & 0,0 \\
\hline 2. $\mid A C-137$ & 38,1 & 0,0 & 0,0 & 0,0 & 0,0 & 0,0 \\
\hline 3. $1 A C-138$ & 49,0 & 0,0 & 0,0 & 0,0 & 0,0 & 0,0 \\
\hline 4. IAC-139 & 46,0 & 11,2 & 0,0 & 0,0 & 0,0 & 0,0 \\
\hline 5. IAC-140 & 39,9 & 0,0 & 0,0 & 0,0 & 0,0 & 0,0 \\
\hline 6. IAC-141 & 41,8 & 0,0 & 0,0 & 0,0 & 0,0 & 0,0 \\
\hline 7. IAC-142 & 29,6 & 0,0 & 0,0 & 0,0 & 0,0 & 0,0 \\
\hline 8. IAC-143 & 55,7 & 6,6 & 0,6 & 0,3 & 0,0 & 0,0 \\
\hline 9. IAC-144 & 40,0 & 0,0 & 0,0 & 0,0 & 0,0 & 0,0 \\
\hline 10. IAC-145 & 52,5 & 9,6 & 3,3 & 0,0 & 0,0 & 0,0 \\
\hline 11. IAC-146 & 56,9 & 0,0 & 0,0 & 0,0 & 0,0 & 0,0 \\
\hline 12. $\mid A C-147$ & 61,3 & 0,0 & 0,0 & 0,0 & 0,0 & 0,0 \\
\hline 13. IAC-148 & 46,6 & 0,0 & 0,0 & 0,0 & 0,0 & 0,0 \\
\hline 14. IAC-149 & 43,9 & 12,4 & 2,0 & 0,4 & 0,0 & 0,0 \\
\hline 15. IAC-150 & 47,6 & 2,9 & 2,9 & 0,8 & 0,0 & 0,0 \\
\hline 16. IAC-151 & 44,3 & 4,3 & 0,0 & 0,0 & 0,0 & 0,0 \\
\hline 17. $\mid A C-152$ & 44,4 & 0,0 & 0,0 & 0,0 & 0,0 & 0,0 \\
\hline 18. $\mid A C-153$ & 45,2 & 14,6 & 1,1 & 0,0 & 0,0 & 0,0 \\
\hline 19. IAC-154 & 57,6 & 21,5 & 2,0 & 0,0 & 0,0 & 0,0 \\
\hline 20. $\mid A C-155$ & 47,9 & 8,3 & 1,3 & 0,0 & 0,0 & 0,0 \\
\hline 21. IAC-156 & 39,1 & 24,4 & 5,0 & 1,4 & 0,0 & 0,0 \\
\hline 22. $\mid A C-157$ & 48,6 & 0,0 & 0,0 & 0,0 & 0,0 & 0,0 \\
\hline 23. IAC- 158 & 46,9 & 0,0 & 0,0 & 0,0 & 0,0 & 0,0 \\
\hline 24. IAC- 159 & 39,7 & 0,0 & 0,0 & 0,0 & 0,0 & 0,0 \\
\hline 25. Alondra-S-46 & 47,6 & 14,6 & 3,4 & 0,0 & 0,0 & 0,0 \\
\hline 26. $\mathrm{BH}-1146$ & 69,8 & 71,9 & 51,1 & 46,3 & 35,4 & 29,7 \\
\hline
\end{tabular}

\section{CONCLUSÖES}

1) As linhagens IAC-156 e IAC-141 salientaram-se quanto à produçāo de grãos em condição de irrigação por aspersão e as linhagens IAC-139, IAC-143, IAC-152 e IAC-157 em condição de sequeiro. Provenientes do agrupamento de genes oriundos de cruzamento entre trigos de inverno e de primavera, elas seriam fontes de alto potencial produtivo ao programa de melhoramento genético do IAC. 
Esses genótipos deveriam ser trabalhados visando a resistência à ferrugem-da-folha, à tolerância à toxicidade de $\mathrm{Al}^{3+} \mathrm{e}$ ao ciclo precoce. As linhagens $\mid \mathrm{AC}-141$, IAC-143, IAC-156 e IAC-157 deveriam, também, ser melhoradas em relação ao porte, e a IAC-141, em relação à resistência ao oídio.

2) As linhagens IAC-142, IAC-144, IAC-145, IAC-146, IAC-148, IAC-149, IAC-150, IAC-152, IAC-153, IAC-157 e IAC-158 e o 'Alondra-S-46' foram resistentes às duas misturas de raças prevalecentes do agente causal de ferugem-do-colmo, em estádio de plântula, em casa de vegetação.

3) As linhagens IAC-143 e IAC-150 mostraram-se resistentes às três misturas de raças prevalecentes do agente causal da ferrugem-da-folha no estádio de plântula. Mostraram-se também resistentes a essa doença em condições naturais de infecção, no campo, em estádio de planta adulta.

4) As linhagens IAC-140, IAC-143, IAC-145, IAC-150 e IAC-153 revelaram-se fontes genèticas para resistência ao oidio.

5) As linhagens IAC-139, IAC-143, IAC-145, IAC-146, IAC-152, IAC-154, IAC-155 e IAC-158 exibiram plantas de porte baixo, não diferindo das do cultivar Alondra-S-46, com exceção da IAC-155, cujas plantas foram mais baixas.

6) A linhagem $\mid \mathrm{AC}-147$ revelou-se fonte genética do caráter espiga comprida; a IAC-142, de maior número de espiguetas por espiga; IAC-146 e IAC-147, de maior número de grãos por espiga; IAC-146, IAC-147 e IAC-148, de maior número de grãos por espigueta, e $\mid A C-157$, de grãos mais pesados.

7) Os genótipos estudados diferenciaram-se quanto à tolerância à toxicidade de $\mathrm{Al}^{3+}$, destacando-se como mais tolerantes as linhagens IAC-143, IAC-149, IAC-150 e IAC-156, que apresentaram um grau de tolerância significativamente menor que a do cultivar $\mathrm{BH}-1146$, utilizado como controle.

\section{SUMMARY}

WHEAT BREEDING:

XXII. EVALUATION OF INBRED LINES ORIGINATED

FROM WINTER $X$ SPRING CROSSES FOR THE STATE OF

SĀO PAULO, BRAZIL

Twenty four inbred lines and the cultivar Alondra-S-46 were compared in trials carried out at different locations of the State of São Paulo, Brazil, on upland and with sprinkler irrigation, taking into account grain yield, yield components and disease resistance. The response of the genotypes for 
two race mixtures of stem rust and for three race mixtures of leaf rust was studied in the greenhouse. In the laboratory, the germplasms were evaluated under Al toxicity using nutrient solutions. The lines IAC-156 and IAC-141 exhibited high yield under sprinkler irrigation and the lines IAC-139, IAC-143, IAC-152 and IAC-157 on upland conditions. In relation to stem rust (Puccinia graminis $f$. sp. tritici) the lines IAC-142, IAC-144, IAC-145, IAC-146, IAC-148, IAC-149, IAC-150, IAC-152, IAC-153, IAC-157 and IAC-158 and the cultivar Alondra-S-46 showed resistance to two race mixtures, at seedling stage. The lines IAC-143 and IAC-150 were resistant at seedling stage to three race mixtures of leaf rust ( $P$. recondita), and also at the stage of adult plant under natural infection out in the field. The lines IAC-140, IAC-143, IAC-145, IAC-150 and IAC-153 showed to be good genetic sources for resistance to powdery mildew. The lines IAC-139, IAC-143, IAC-145, IAC-146, IAC-152, IAC-154, IAC-155, and IAC-158 and the cultivar Alondra-S-46 exhibited short plants. The line IAC-147 showed as a good genetic source for head length; IAC-142 for high number of spikelets per spike; IAC-146 and IAC-147 for number of grains per head; IAC-146; IAC-147 and IAC-148 for high number of grains per spikelet, and IAC-157 for high grain weight. The lines IAC-143, IAC-149, IAC-150 and IAC-156 were the most tolerant in relation to Al toxicity but significantly less tolerant than the cultivar $\mathrm{BH}-1146$ used as control.

Index terms: wheat, plant breeding; cultivar; inbred lines; grain yield; stem and leaf rusts; aluminum toxicity.

\section{AGRADECIMENTOS}

Os autores agradecem ao Centro Nacional de Pesquisa de Trigo (EMBRAPA) os testes de resistência às ferrugens-do-colmo e da-folha em casa de vegetação.

\section{REFERÊNCIAS BIBLIOGRÁFICAS}

BARCELLOS, A.L. Ferrugem da folha do trigo no Brasil, em 1984 e 1985: ocorrência e virulência. In: REUNIÄO NACIONAL DE PESQUISA DE TRIGO, 14., Londrina, 1986. Resultados de pesquisa do Centro Nacional de Pesquisa de Trigo apresentados na XIV Reunião Nacional de Pesquisa de Trigo. Passo Fundo, EMBRAPA-CNPT, 1986. p.117-131.

CAMARGO, C.E.O. Melhoramento genético do trigo para irrigação de inverno nas condiçōes do Estado de Sāo Paulo. In: SIMPÓSIO SOBRE O MANEJO DE ÁGUA NA AGRICULTURA, Campinas, 1987. Campinas, Fundação Cargill, 1987. p.134-174.

; FELICIO, J.C.; FREITAS, J.G.; BARROS, B.C.; CASTRO, J.L. \& SABINO, J.C. Melhorarnento do trigo. XII. Comportamento de novas linhagens e cultivares de trigo no Estado de São Paulo. Bragantia, Campinas, 44(2):669-685, 1985.

\& OLIVEIRA, O.F. Tolerância de cultivares de trigo a diferentes niveis de aluminio em soluçāo nutritiva e no solo. Bragantıa, Campinas, 40:21-31, 1981. 
COELHO, E.T. Avaliação de resistência à ferrugem do colmo das cultivares dos ensaios regionais de rendimento de variedades de trigo do Cone Sul (ERCOS). In: REUNIÄO NACIONAL DE PESQUISA DE TRIGO, 14., Londrina, 1986. Resultados de pesquisa do Centro Nacional de Pesquisa de Trigo apresentados na XIV Reuníao Nacional de Pesquisa de Trigo. Passo Fundo, EMBRAPA-CNPT, 1986. p.101-110.

HANSON, H.; BORLAUG, N.E. \& ANDERSON, R.G. Wheat in the third world. México, International Maize and Wheat Improvement Center, Westview Press, 1982. 174p.

MEHTA, Y.R. Doenças do trigo e seu controle. São Paulo, Ceres, 1978. 190p.

MOORE, D.P.; KRONSTAD, W.E. \& METZGER, R.J. Screening wheat for aluminum tolerance. In: WORKSHOP ON PLANT ADAPTATIONS TO MINERAL STRESS IN PROBLEM SOILS, Beltsville, Maryland, 1976. Proceedings. p.287-295.

POEHLMAN, J.M. Breeding wheat. In: Rinehart and Winston, 1959. p.100-127.

SĀO PAULO, Secretaria de Agricultura e Abastecimento. Relatórios do acordo entre a S.A.A., através do Instituto Agronômico, e as Cooperativas Rurais do Vale do Paranapanema. Campinas, 1979-1987.

SCHRAM, W.; FULCO, W.S.; SOARES, M.H.G. \& ALMEIDA, A.M.P. Resistência de cultivares de trigo em experimentação ou cultivo no Rio Grande do Sul às principais doenças fúngicas. Agronomia Sulriograndense, Porto Alegre, 10:31-39, 1974. 